\title{
Two mega sand and dust storm events over northern China in March 2021: transport processes, historical ranking and meteorological drivers
}

Ke Gui ${ }^{1}$, Wenrui Yao ${ }^{1,2}$, Huizheng Che ${ }^{1, *}$, Linchang An ${ }^{3}$, Yu Zheng ${ }^{1}$, Lei Li $^{1}$, Hujia Zhao ${ }^{4}$, Lei Zhang ${ }^{1}$, Junting Zhong ${ }^{1}$, Yaqiang Wang ${ }^{1}$, Xiaoye Zhang ${ }^{1}$

${ }^{1}$ State Key Laboratory of Severe Weather \& Key Laboratory of Atmospheric Chemistry of CMA, Chinese Academy of Meteorological Sciences, Beijing, 100081, China

${ }^{2}$ Department of Atmospheric and Oceanic Sciences \& Institute of Atmospheric Sciences, Fudan University, Shanghai, 200438,

10 China

${ }^{3}$ National Meteorological Center, CMA, Beijing 100081, China

${ }^{4}$ Institute of Atmospheric Environment, China Meteorological Administration, Shenyang, 110166, China

Correspondence to: Huizheng Che (chehz@cma.gov.cn)

Abstract. Although a remarkable reduction in the frequency of sand and dust storms (SDSs) in the past several decades has

15 been reported over northern China (NC), two unexpected mega SDSs occurred on March 15-20, 2021 and March 27-29, 2021 (abbreviated as the "3.15" and "3.27" SDS events), which has reawakened widespread concern. This study characterizes the origins, transport processes, magnitudes of impact, and meteorological causes of these two SDS events using a long-term (2000-2021) dust optical depth (DOD) dataset retrieved from MODIS measurements and a comprehensive set of multiple satellite and ground-based observations combined with atmospheric reanalysis data. During the 3.15/3.27 event, the invasion

20 of dust plumes greatly degraded the air quality over large areas of NC, reaching extremely hazardous levels, with the maximum daily mean $\mathrm{PM}_{10}$ concentration of $7058 \mu \mathrm{g} \mathrm{m}^{-3}\left(2670 \mu \mathrm{g} \mathrm{m}^{-3}\right)$ recorded on March 15 (28). CALIOP observations show that during the 3.15 event the dust plume was lifted to an altitude of $4-8 \mathrm{~km}$, and its range of impact extended from the dust source to the eastern coast of China. In contrast, the lifting height of the dust plume during the 3.27 event was lower than that during 3.15 event, which was also confirmed by ground-based Lidar observations. The MODIS-retrieved DOD data registered these

25 two massive SDS events as the most intense episode in the same period in history over the past two decades. These two extreme SDS events were associated with both atmospheric circulation extremes and local meteorological anomalies that favored enhanced dust emissions in the Gobi Desert (GD) across southern Mongolia and NC. Meteorological analysis revealed that both SDS events were triggered by an exceptionally strong Mongolian cyclone generated at nearly the same location (along the central and eastern plateau of Inner Mongolia) in conjunction with a surface-level cold high-pressure system at the rear, albeit

30 with differences in magnitude and spatial extent of impact. In the GD, the early melting of spring snow caused by near-surface temperature anomalies over dust source regions, together with negative soil moisture anomalies induced by decreased 
precipitation, formed drier and barer soil surfaces, which allowed for increased emissions of dust into the atmosphere by strongly enhanced surface winds generated by the Mongolian cyclone.

\section{Introduction}

Sand and dust storms (SDSs) are a highly hazardous and disastrous weather type formed when strong winds draw large amounts of mineral dust aerosols from dry, bare soil surfaces into the atmosphere, and are a serious environmental problem that many countries adjacent to and downwind of dust source areas are or have been facing (Zhang et al., 2003a; Wu et al., 2021; Yu et al., 2021). East Asia is the world's second largest dust source, contributing about $40 \%(\sim 8-13 \mathrm{Tg})$ of the global dust loading, with the largest contribution from the Taklamakan and Gobi deserts (TD and GD) located in northern China (NC) (Kok et al., 2021). East Asian dust can be transported to large parts of China (An et al., 2018), Japan, Korea, the Pacific Ocean (Zhang et al., 2003b; Tan et al., 2017), and as far as the west coast of the United States (Gong et al., 2006; Duncan Fairlie et al., 2007; Zhao et al., 2008), where it can affect the regional air quality, human health and many different socioeconomic activities, and modify Earth's energy balances directly by interactions with radiation and indirectly by interactions with clouds and ecosystems (e.g., Rosenfeld et al., 2001; Kok et al., 2017). Most SDSs in East Asia tend to occur in spring (March, April and May), and can mainly be attributed to two aspects: (1) the low cover of vegetation in spring, accompanied by low precipitation, leads to a dry and loose soil surface layer, which directly provides a favorable material source for the occurrence of SDSs; and (2) the frequent cyclones (mostly Mongolian cyclones) with strong northwesterly winds in spring combined with the unstable atmospheric stratification in the afternoon provide favorable dynamical conditions for the occurrence of SDSs (Chen et al., 2017a; Rodríguez et al., 2012).

Given the considerable environmental and climatic effects of dust aerosols, numerous studies have investigated the sources, spatial and temporal distribution, and long-term variability of spring dust aerosol loading in East Asia, and their drivers. Broadly speaking, these studies have revealed, from different perspectives, that dust emissions and loading as well as the frequency of SDSs in spring in East Asia have undergone a remarkable decline in the past several decades (e.g., Gong et al., 2004; Wang et al., 2018; Liu et al., 2020; Yao et al., 2021; Gui et al., 2021). The negative trends of spring dust aerosols in East Asia are mainly attributed to the decline in surface wind speeds, which may be related to the weakened temperature gradient at mid-latitudes caused by the enhancement of the Arctic amplification effect and weakening of the polar vortex (An et al., 2018; Liu et al., 2020). In addition to the contribution from wind speed, the reduction in dust aerosols is also closely associated with the increases in vegetation cover (VC), precipitation (PPT), and volumetric soil water (VSW) in the dust source areas. Increased VC is not only driven by natural conditions such as temperature and PPT in mid- and high-latitude regions, but is often attributed to largescale land-use management activities (e.g., afforestation in NC) (Chen et al., 2019).

In the context of a remarkable reduction in the frequency of SDSs in East Asia, and especially the absence of an SDS for more than 10 years in NC, two unexpected extreme SDSs occurred on March 15-20, 2021 and March 27-29, 2021 (abbreviated as the "3.15" and "3.27" SDS events), both of which greatly degraded the air quality in most of China. Fig. 1 presents a snapshot 
panorama of the dust plume invading NC captured by the Visible Infrared Imaging Radiometer Suite (VIIRS) aboard the Suomi National Polar-Orbiting Partnership (Suomi NPP) satellite on March 15 and March 28, 2021, respectively. The satellite image on March 15 (Fig. 1a) displays a dense dust plume that ravaged a large part of China, with an area of more than 3.8 million $\mathrm{km}^{2}$, accounting for about $40 \%$ of China's land area. Compared with March 15, satellite images on March 27 show a weaker dust plume intensity, along with a reduced eastward influence and scope (Fig. 1b). These two events received extensive media exposure as a result of their severity and enormous impacts on large areas. For example, both the World Meteorological (https://edition.cnn.com/2021/03/15/asia/beijing-sandstorm-decade-intl-hnk) described the 3.15 SDS event as the biggest SDS in almost a decade. Liang et al. (2021) revealed the changes in dust composition and transport processes during the 3.15 SDS event in NC using geochemical analyses and remote sensing. Yin et al. (2021) utilized site observations, reanalysis data, and historical simulation outputs from CMIP 6 (phase 6 of the Coupled Model Intercomparison Project) to analyze the climate anomalies in dust source areas and the dynamical mechanisms of Mongolian cyclones influencing dust occurrence and development, and revealed that the climate variabilities at different latitudes and synoptic disturbances jointly facilitated the strongest SDS event in NC over the past decade. Although these two studies have strengthened our understanding of the 3.15 mega SDS event in 2021, the sources, three-dimensional evolutionary features during transport processes, historical ranking, and local meteorological anomalies of the 3.15 and 3.27 SDS events have not yet been elucidated.

In this study, long-term Level-2 aerosol property data from the Moderate Resolution Imaging Spectroradiometer (MODIS), combined with a variety of multiple satellite and ground-based observations as well as aerosol reanalysis data from the ModernEra Retrospective Analysis for Research and Applications, version 2 (MERRA-2) and meteorological reanalysis from the Fifth major global reanalysis produced by ECMWF (ERA5), were used to track the three-dimensional transport characteristics of the SDS and examine its impact on air quality in NC. To be specific, this study will seek to (1) describe the three-dimensional vertical evolution features of the dust plumes during transport, (2) place the intensity of these two SDSs, with dust optical depth (DOD) as an indicator, in the context of the last two decades for NC and its sub-regions, (3) understand the circulation patterns that contribute to the formation of SDSs, and (4) explore the local meteorological anomalies that lead to changes in the condition of surface soil layers in dust source areas that favor enhanced dust emissions.

\section{Data and methods}

\subsection{Satellite datasets}

\subsubsection{MODIS-retrieved DOD}

DOD, as one of the key parameters for characterizing the optical properties of dust aerosols, describing the columnar optical depth due to the extinction by mineral dust particles, has been widely used in dust-related studies (e.g., Pu and Ginoux, 2016; Song et al., 2021; Gkikas et al., 2021; Logothetis et al., 2021). The long-term DOD data in March for NC were derived 

the radiance received by the blue channels to detect land aerosol loadings with bright surfaces (e.g., desert). In this study, MODIS DB Collection 6.1 aerosol products from both the Terra (MOD04_L2) and Aqua (MYD04_L2) platforms were used. Before retrieving DOD values, aerosol products including aerosol optical depth (AOD) at 550 nm, single-scattering albedo (SSA), and the Ångström exponent were first interpolated to a regular $0.1^{\circ} \times 0.1^{\circ}$ grid using the nearest-neighbor algorithm. For AOD, only the AOD data flagged as good quality (quality flag $=2$ ) or very good quality (quality flag = 3) was used, which effectively eliminated the influence of low-quality AOD on the DOD retrieval. Then, gridded DOD data were retrieved using these parameters as the input following the methods of Pu and Ginoux (2018). In Pu and Ginoux (2018), the DOD over land was derived from MODIS DB aerosol products by using a continuous function relating the Ångström exponent to the finemode AOD established by Anderson et al. (2005) based on in-situ data. This approach, as summarized in Eq. (1), allows the separation of coarse-mode dust and fine particle contributions from the AOD:

$$
\begin{gathered}
\mathrm{DOD}=\mathrm{AOD} \times\left(0.98-0.5089 \alpha+0.0512 \alpha^{2}\right) \\
(\omega<1.0, \alpha<0.3),
\end{gathered}
$$

where $\alpha$ is the Ångström exponent and $\omega$ is the SSA. The DOD is obtained only when $\omega$ is less than 1.0 and $\alpha$ is less than 0.3 for dust owing to its predominance of coarse modes and its absorption of solar radiation. Note that the DOD here denotes the coarse-mode contribution of dust only and does not include its fine-mode contribution. Estimates by Kok et al. (2017) suggest that fine-mode dust accounts for less than $10 \%$ of the total dust emissions. It is for this reason that the comparison results, using Aerosol Robotic Network (AERONET) observations as a reference, show the DOD values for both Terra and Aqua to be slightly underestimated, as demonstrated by the uncertainties of 0.10+0.48 DOD and 0.08+0.52 DOD, respectively (Pu and Ginoux, 2018). Nevertheless, when comparing the MODIS-derived DOD climatology with both AERONET observations and the DOD retrieved from the Cloud-Aerosol Lidar with Orthogonal Polarization (CALIOP) aboard the Cloud-Aerosol Lidar and Infrared Pathfinder Satellite Observation (CALIPSO) satellite, the climatological mean of the MODIS DOD generally compares well with AERONET and CALIOP, not only at the site scale, but also in terms of spatial distribution.

To improve the spatial coverage of the limited DOD retrieval and also to incorporate inputs from both morning ( 10:30 local time for Terra) and afternoon observations ( 13:30 local time for Aqua), the combined daily DOD was derived by averaging the Terra and Aqua DODs when both sets of information were available, or by using either the Terra or Aqua DOD when only one set of information was available. Subsequently, these daily DOD data were averaged to monthly average DODs by requiring a minimum of three valid daily DOD retrievals in a month. This combined March DOD dataset is available from 2000 to 2021 (until 2003 from Terra, and thereafter a combination of both Terra and Aqua).

\subsubsection{CALIOP aerosol extinction profiles}

To characterize the vertical profile of the dust plume, the Level 2 daily $532 \mathrm{~nm}$ aerosol profile product (05kmAPro, V4.21) from CALIOP/CALIPSO (Winker et al., 2010) was used. In addition to providing vertical extinction profiles for total aerosols, this product also provides vertical feature masks that can be used to classify an aerosol layer into one of seven subtypes: dust, 
polluted dust, polluted continental, smoke, clean continental, clean marine, and dusty marine. Based on this, dust extinction profiles were further extracted by using the bitmask corresponding to the dust aerosol type. To reduce uncertainty, only highquality extinction profile data with a CAD (cloud aerosol discrimination) score of between -100 and -20 were used.

\subsubsection{Suomi NPP VIIRS Imagery and OMPS UVAI}

The near real-time corrected reflectance imagery from VIIRS aboard the Suomi NPP satellite (Hillger et al., 2013) was used to monitor the generation and movement of dust plumes. The Ultraviolet Aerosol Index (UVAI) from the Ozone Mapping and Profiler Suite Nadir Mapper (OMPS-NM) aboard the Suomi NPP satellite (Kablick et al., 2020) was utilized to distinguish absorbing aerosols, such as dust and elevated smoke, from non-absorbing aerosols. The OMPS UVAI is calculated from normalized radiances using two wavelength pairs at 340 and $378.5 \mathrm{~nm}$. The UVAI has been widely used to identify and track the emissions and long-range transport of dust from desert dust storms (e.g., Pu and Jin, 2021; Tao et al., 2021), even over clouds and in areas of snow and ice. In this study, the Level 2 UVAI swath data in March 2021 were aggregated into $0.5^{\circ} \times$ $0.5^{\circ}$ grids to track the dust plume movement.

\subsection{ERA5 and MERRA-2 reanalyses}

\subsubsection{ERA5 atmospheric reanalysis}

ERA5 reanalysis data (Hersbach et al., 2020), at a $0.25^{\circ} \times 0.25^{\circ}$ horizontal resolution, for March 2000-2021, were used to investigate both atmospheric circulation extremes and the local meteorological anomalies associated with two strong SDSs in March 2021. In this study, both daily and monthly variables were used, the former including daily wind fields at $10 \mathrm{~m}, 850$ $\mathrm{hPa}$ and $700 \mathrm{hPa}$ and daily sea level pressure (SLP), geopotential height (GH) and temperature fields at $700 \mathrm{hPa}$, which were used to explore the atmospheric conditions driving the emission, transport and deposition processes of the two extreme SDSs; and the latter including temperature at $2 \mathrm{~m}$, snow depth (SD), PPT and VSW at 0-7 $\mathrm{cm}$ depth, which were used to resolve the historical meteorological anomalies driving the March 2021 dust anomaly. As a complement, the hourly SLP and 10-m wind field on March 14 were used to analyze the atmospheric circulation background for the day before the outbreak of the 3.15 event.

\subsubsection{MERRA-2 aerosol reanalysis}

MERRA-2 products from the NASA's GMAO (Global Modeling and Assimilation Office) were used to identify the sources of the two SDS events. The MERRA-2 reanalysis was generated using the Goddard Earth Observation System (GEOS5) with a $3 \mathrm{D}$ variational data assimilation system that assimilates a large number of observational datasets (Buchard et al.,

155 2017). The MERRA-2 hourly dust emissions at a $0.5^{\circ} \times 0.625^{\circ}$ horizontal resolution during these two SDS events were used. GEOS-5, based on Ginoux et al. (2001), simulated dust emissions, which were resolved in five size bins with diameter bounds at $0.1,1.0,1.8,3.0,6.0$, and $10.0 \mu \mathrm{m}$, respectively. By comparing with satellite and ground-based observations, Yao et al., 
(2020) demonstrated the ability of MERRA-2 in characterizing the three-dimensional evolution of dust aerosols during an extreme SDS event in East Asia.

\subsection{Observation datasets}

\subsubsection{PM10 concentrations from the CNEMC network}

In response to air pollution, the Chinese government established a comprehensive network across the nation [namely, the China National Environmental Monitoring Center (CNEMC) network] at the end of 2012 to monitor the outdoor air quality for particulate matter (PM), ozone, and gas precursors. In this study, the impacts of the dust plume on air quality in NC during these two SDS events were investigated using the daily $\mathrm{PM}_{10}$ (PM with an aerodynamic diameter smaller than $10 \mu \mathrm{m}$ ) concentration from the CNEMC network.

\subsubsection{Ground-based lidar observations from AD-Net}

AD-Net (Shimizu et al., 2004; Sugimoto et al., 2008) is a lidar network for continuous monitoring of the vertical profile of dust and other aerosols (e.g., anthropogenic aerosols, biomass burning aerosols, and volcanic ash aerosols), with the aim of investigating the implications of aerosols on climate, environment and health in East Asia. AD-Net is composed of a dualwavelength (1064 nm, $532 \mathrm{~nm}$ ) polarization-sensitive Mie-scattering lidar (Sugimoto et al., 2008), which has been distributed to more than 20 sites in East Asia. In this study, the aerosol optical property profiles provided by an AD-Net site named "Zamynuud" were used to explore the impacts of long-range dust transport on downstream areas. The geographical location of the "Zamynuud" site is shown in Fig. 1. The variables used in the analysis were the $532 \mathrm{~nm}$ aerosol extinction coefficient

175 (AEC), volume depolarization ratio (VDR), and attenuated backscatter coefficient (ABC). The temporal resolution of the ADNet lidar observations is $15 \mathrm{~min}$ and the vertical resolution is $30 \mathrm{~m}$. For more details on the quality checking and processing procedures applied to the lidar observational data from AD-Net, see Shimizu et al. (2004) and Shimizu et al. (2010).

\section{Results and discussion}

\subsection{Observational characterizations of the two SDS events in March 2021}

\subsubsection{Tracking dust transport processes from ground-based observations}

The transport processes of dust plumes from the two mega SDS events that ravaged NC and their impact on air quality are depicted through CNEMC $\mathrm{PM}_{10}$ (as an indicator of coarse-mode dust aerosols) observations. Fig. 2 shows the daily mean $\mathrm{PM}_{10}$ maps for the 3.15 and 3.27 events, respectively. CNEMC station records show that, during the 3.15 event, $\mathrm{PM}_{10}$ concentrations first reached a maximum on March 15 in most of NC, including Gansu, southwestern Inner Mongolia, Ningxia, northern Shaanxi, northern Shanxi, Hebei and Beijing, with a single-site daily mean maximum of $7058 \mu \mathrm{g} \mathrm{m}^{-3}$, due to dust plume deposition. In the areas affected by the dust plume described above, the 24-h $\mathrm{PM}_{10}$ concentrations far exceeded the 
newly released air quality guidelines $\left(45 \mu \mathrm{g} \mathrm{m}^{-3}\right)$ and Interim Target-1 $\left(150 \mu \mathrm{g} \mathrm{m}^{-3}\right)$ set by the World Health Organization (WHO, 2021), reaching extremely hazardous levels for human health. Even more exaggerated than that on March 15, the instantaneous surface $\mathrm{PM}_{10}$ concentrations exceeded the monitoring threshold of $9985 \mu \mathrm{g} \mathrm{m}{ }^{-3}$ at eight sites (Fig. S1). This magnitude is unprecedented since surface $\mathrm{PM}_{10}$ concentrations in China were first recorded. On March 16, a large amount of dust aerosol was further transported downstream, and its impact spread to Shandong, Henan, and the northern part of Jiangsu and Anhui, with a single-site daily mean maximum of $4943 \mu \mathrm{g} \mathrm{m}^{-3}$. On March 17, under the influence of southeasterly winds blowing from the Yellow Sea, the dust plume stopped continuing southwards and began to reflux and gradually deposit, and the intensity of its influence weakened significantly compared with the previous two days. Nevertheless, PM $_{10}$ concentrations remained at extremely serious pollution levels in the areas near the dust source, such as Gansu, Ningxia, and southwestern Inner Mongolia. On March 18 and 19, the daily mean $\mathrm{PM}_{10}$ concentration gradually decreased to below $200 \mu \mathrm{g} \mathrm{m}^{-3}$ in the downstream area of the dust source except in Gansu, Inner Mongolia and Qinghai. The dust plume eventually began to dissipate on March 20 under the action of strong northwesterly winds.

A week after the end of the 3.15 event, a new dust plume (i.e., the 3.27 event) swept across most of the north again. Overall, the 3.27 event was weaker than the 3.15 event in terms of magnitude, scope and duration of the dust impact. Specifically, the 3.27 event started on 27 March, reached its peak on 28 March, and then gradually dissipated on 29 March. Despite its relatively short duration, the impact of the 3.27 event (especially on March 28) still covered areas including southern Inner Mongolia, Hebei, Shanxi, and Shandong. $\mathrm{PM}_{10}$ observation records show that the daily mean $\mathrm{PM}_{10}$ concentration exceeded $1000 \mathrm{\mu g} \mathrm{m}^{-3}$ at several sites, with a single-site daily mean maximum of $2670 \mu \mathrm{g} \mathrm{m}^{-3}$. Notably, this event had a shortterm explosive contribution to surface $\mathrm{PM}_{10}$ concentrations that still cannot be ignored, as demonstrated by six sites where the instantaneous $\mathrm{PM}_{10}$ concentrations exceeded the upper limit of the observed threshold $\left(9985 \mu \mathrm{g} \mathrm{m}^{-3}\right)\left(\mathrm{Fig}_{\mathrm{g}} \mathrm{S} 1\right)$.

The dynamic evolution of the dust plume in the vertical direction during these two SDS events was characterized using continuous ground-based Lidar observations. Fig. 3 shows the vertical evolution of the aerosol optical properties, including the AEC, ABC and VDR, for the AD-Net site named "Zamynuud" located at the edge of Inner Mongolia. Influenced by the 3.15 mega SDS event, the dust plume $\left(\mathrm{ABC}>0.005 \mathrm{~km}^{-1} \mathrm{sr}^{-1}\right.$ and VDR >0.2) was first transported to the near-surface layer from $6 \mathrm{~km}$ altitude at 04:00 to 18:00 CST (China standard time) on March 16, and formed an intense aerosol layer with an AEC larger than $0.5 \mathrm{~km}^{-1}$ at an altitude of about $1.5 \mathrm{~km}$. Subsequently, in the altitude range of 0-2 km, the thickness of the aerosol layer continuously expanded to about $1 \mathrm{~km}$ and remained in a stable phase for more than 12 hours. At 18:00 CST March 17, as the near-surface aerosols dissipated, the two dust plumes were once again transported to over north-central Inner Mongolia through two different altitude pathways (starting at $2 \mathrm{~km}$ and $4 \mathrm{~km}$ altitude, respectively). By this time and until 18:00 CST March 18, the dust plume located in the lower layers was transported to the near-surface, which enhanced the AEC to $0.2 \mathrm{~km}^{-1}$ and formed a dust aerosol layer with a thickness of $\sim 2 \mathrm{~km}$. In contrast, the strong dust plume $\left(\mathrm{AEC}>\mathrm{km}{ }^{-1}, \mathrm{ABC}>\right.$ $0.02 \mathrm{~km}^{-1} \mathrm{sr}^{-1}$, and VDR > 0.3) carrying a large amount of dust aerosols from the upper layers experienced a longer transport time (about 1 day) than the dust plume located at the lower layers to reach the near-surface at 18:00 CST March 19. After this, the dust plume gradually dissipated as the dust aerosol diffused and deposited. 
Similar to the 3.15 event, north-central Inner Mongolia was also influenced by the high-altitude, long-range transport of dust plumes during the 3.27 event, but the transport started at a much lower altitude. Specifically, the high-altitude transport of the dust plume started at an altitude of $3 \mathrm{~km}$ at 08:00 CST March 27 and reached the near-surface 5 hours later. This transport process allowed for a rapid accumulation of near-surface dust aerosols, resulting in the surface AEC increasing to about 1.0 $\mathrm{km}^{-1}$.

\subsubsection{Tracking dust transport processes from space-based observations}

Satellite observations provide a broader perspective than ground-based observations and are able to capture regional evolutionary features during dust transport. Fig. S2 shows the MODIS daily AOD maps during the 3.15 and 3.27 events at a frequency of every other day. While the ratio of DOD to AOD (Fig. S3) suggests that the aerosol plume was mainly composed of dust particles, the MODIS-retrieved DOD (Fig. 4) shows the magnitude of the two dust transport processes. In this study, MODIS retrievals from both Aqua and Terra were incorporated to represent the daily DOD or AOD with an improved spatial coverage. The spatial absence of DOD is mainly attributed to the presence of clouds and the limitations of the MODIS AOD retrieval algorithms. Overall, the evolutionary pattern of DOD is consistent with that of ground-based PM $\mathrm{P}_{10}$ observations (see Fig. 2). On the first day of the 3.15 event (March 15), it is clear from these maps that there were dust plumes as wide as 2500 $\mathrm{km}$ (confined within $40-50^{\circ} \mathrm{N}$ ), crossing most of $\mathrm{NC}$ in a meandering path. Due to the large amount of mineral dust aerosols emitted into the atmosphere, a resultant peak DOD of about 3.0 occurred on March 15-17. From March 18 to March 20 , the DOD in the area near the source and downstream gradually decreased as the deposition and emission of dust weakened. Early in the 3.27 event (March 27), MODIS captured an enhanced polluted hotspot (DOD > 2.5), which was located in southern Mongolia. This suggests that the 3.27 event was associated with intensified emissions in this region. On March 28 , dust plumes carrying large amounts of dust aerosols were transported to the North China Plain (NCP) and Liaoning under the action of atmospheric circulation, with the DOD reaching the range of 2-3. Notably, an enhancement of DOD at the dust source on March 28 was not captured, which implies that the intensity of dust emissions was significantly lower on March 28 than on March 27.

To better capture the full spatial transport pathway of the dust plume, especially in cloud-covered regions where MODIS retrievals were not available, the daily map of the OMPS UVAI is presented (Fig. 5). It is clear that the UVAI map is able to provide a more spatially continuous evolution of the dust plume than the satellite-retrieved AOD or DOD map. Overall, the transport pathway of the dust plume during the two SDS events was mainly controlled by the movement trajectory of a cyclone (namely, the Mongolian cyclone). On March 15, a powerful cyclone (maximum wind speed more than $30 \mathrm{~m} \mathrm{~s}{ }^{-1}$ at $850 \mathrm{hPa}$ ) located in northeastern China (NEC) pulled dust aerosols emitted from the dust source into the atmosphere, forming a dust belt with a UVAI ranging within about 2-4. From March 16 to March 17, the UVAI successfully captured the dust plumes carried by the cyclone to the Yellow Sea, Sea of Japan, and downstream land areas (including Korea and Japan). On March 18, substantial dust emissions from the GD contributed to a hotspot with the UVAI exceeding 2.5. Subsequently, these dust aerosols began to transport downstream driven by northwesterly winds, eventually forming a local pollution hotspot with 
UVAI > 3.0 near the Bohai Sea. However, this feature was not captured by the MODIS retrievals (see Fig. S2). This further

highlights the advantage of the UVAI in cloudy conditions. During the 3.27 event, a cyclone originating in eastern Mongolia picked up the dust aerosols from the dust source and transported them to the NCP, Liaoning, Jilin, Heilongjiang, and the northwestern Sea of Japan over the next two days as the cyclone developed and strengthened and moved eastwards. Notably, it was found that, although the dust plume near the NCP on March 15 captured by OMPS was morphologically similar to the dust plume on March 28, the latter was located slightly to the south. The differences in the spatial location of the dust plume were mainly caused by the differences in the intensity, extent and location of the cyclones on these two days.

As a supplement to ground-based Lidar observations, space-based CALIOP/CALIPSO observations were also utilized in this study to better characterize the vertical evolutionary structure of the dust plume in space over time. Fig. 6 displays the CALIOP aerosol subtypes and AEC for the "dust" type over north-central China (March 15 and 27), the region spanning the Yellow Sea and NEC (March 16), and the region spanning northern Beijing, the Bohai Bay, and the eastern coast (March 28). Note that when the dust concentration is extremely high, the attenuation signal received by CALIOP may be biased beneath the thick dust layer, which may result in failed retrievals of the AEC in which "no dust" is implied when in fact they may actually contain some dust (Pu et al, 2021).

On March 15, dust and polluted dust were the dominant aerosol types on the CALIOP trajectory pathway, with large amounts of dust aerosols forming an enhanced dust layer within $2-6 \mathrm{~km}$ between $36^{\circ} \mathrm{N}$ and $41^{\circ} \mathrm{N}$, where dust with AEC > 1.0 $\mathrm{km}^{-1}$ was located in the near-surface layer $(2-3 \mathrm{~km})$. On the following day, March 16 , the dust plume was continuously transported downstream by the topography and wind and lifted to an altitude of more than $8 \mathrm{~km}$ by the interaction of wind and topography, but its strength was largely reduced. Due to the deposition process along the transport path that significantly reduces the dust loading, no obvious extinction features were found in the lower atmosphere of the Yellow Sea.

In contrast, the lifting altitude of the dust plume on March 15 was higher than that on March 27, with the top of the dust plume $\left(\mathrm{AEC}>0.05 \mathrm{~km}^{-1}\right.$ ) at about $5 \mathrm{~km}$. The difference in lifting altitude of the dust plume between the two days was also confirmed by ground-based lidar observations near the two CALIOP/CALIPSO tracks (Fig. 3). Nevertheless, CALIOP detected a dust layer spanning $30^{\circ} \mathrm{N}$ to $45^{\circ} \mathrm{N}$ on March 27 , with an enhanced AEC $\left(>1.0 \mathrm{~km}^{-1}\right)$ located mainly between $39^{\circ}$ and $45^{\circ}$ (i.e., near the GD). After 1 day of transport (March 28), these dust plumes were transported to Bohai Bay and the eastern coast and were mainly constrained to the altitude range of $0-3 \mathrm{~km}$ between $36^{\circ}$ and $40^{\circ} \mathrm{N}$. The substantial accumulation of dust in the lower atmosphere directly led to a significant deterioration of the near-surface air quality (see Fig. 2h), which is also confirmed by the VIIRS image (Fig. 1b) and OMPS UVAI (Fig. 5h).

\subsection{Identification of dust source areas from MERRA-2 aerosol reanalysis}

Currently, models still face huge challenges in accurately quantifying dust emissions, due to limitations such as uncertainties in the dust source locations and dust emission parameterization schemes (Kok et al., 2020). Aerosol reanalysis involving the assimilation of a large number of observations is considered a valuable tool for evaluating dust processes in climate models (Wu et al., 2020; Zhao et al., 2021). Admittedly, aerosol reanalysis also carries some uncertainties; however, 
it was still expected to provide a valuable reference for identifying the sources of these two dust processes. Dust emissions during these two SDS events were characterized by MERRA-2 aerosol reanalysis data. Fig. 7 displays the MERRA-2 daily mean dust emissions for all size bins during the 3.15 and 3.27 events. Overall, in both SDS events, MERRA-2 identified two sources of enhanced dust emissions: one in the TD and the other in the GD across southern Mongolia and northwestern Inner Mongolia. Although dust emissions from the TD were more intense than those from the GD on most days, dust particles from the TD were not susceptible to be transported outside the Tarim Basin owing to the prevailing surface easterly winds (see wind fields in Figs. 2 and 5). Typically, the TD being surrounded by mountains on three sides, and the surface wind being dominated by an easterly with low speeds at high altitudes in spring, results in most spring dust over the TD being re-deposited after uplift (Chen et al., 2017b). Therefore, the source of these two SDS events can be basically determined as the GD. In the following, the focus is mainly on the variability of dust emissions in the GD.

As shown in Fig. 7, on March 15, MERRA-2 captured intensified dust emissions in the GD within Inner Mongolia, with a daily mean dust emission level of $5-20 \mu \mathrm{g} \mathrm{m}^{-2} \mathrm{~s}^{-1}$ and a daily maximum hourly dust emission level of more than $50 \mu \mathrm{g} \mathrm{m}^{-2}$ $\mathrm{s}^{-1}$ (Fig. S4). Such a level of dust emission intensity was bound to have been largely responsible for the exploding surface $\mathrm{PM}_{10}$ concentrations in most areas of NC. It is worth noting that on March 15 the dust emissions from the GD located in northwestern Inner Mongolia were significantly higher than the intensity of dust emissions from the GD located in southern Mongolia, which raises the question as to whether the GD in China was the original source of the 3.15 SDS event. Fig. 8a further illustrates the MERRA-2 dust emissions and surface wind field for the day before the 3.15 event (March 14). The results show that the 3.15 SDS event was in fact first triggered by enhanced dust emissions from the GD in southern Mongolia, followed by the transport of large amounts of blowing dust aerosols into China by northerly winds that were enhanced by mixing with locally emitted dust aerosols. This suggests that, apart from the dust source areas in China, changes in surface conditions in the dust source areas of neighboring countries also need to be given more attention to reduce the frequency and effects of SDSs, especially in the context of climate change (Wu et al., 2021). In the next 2 days (March 16 and 17), dust from the GD continued to be emitted into the atmosphere, but its intensity tended to weaken. From March 18 to 20 , although the emission of dust was enhanced compared with the previous two days, the "blown-up" dust aerosols were usually confined to the local area or lifted to higher altitudes, and did not have much impact on the near-surface in the downstream region.

On March 28, MERRA-2 identified that the second dust process originated from a dust source similar to the first process but in a slightly more easterly location. In terms of the dust emission intensity, although the emission intensity from dust sources within Inner Mongolia during the second process was lower than that of the first process, the intensity within Mongolia was significantly higher than that of the first process. Combining the wind field (Fig. 5g), satellite observations (UVAI) and dust emissions diagnosed by MERRA-2, it can be inferred that the 3.27 event initially originated from the dust source area in southeastern Mongolia. In the following two days (March 28 and 29), a significant reduction in the intensity of dust emissions was observed. 


\subsection{Atmospheric circulation patterns for controlling the emission and transport of dust}

Most of the SDSs in NC have long been typically related to Mongolian cyclones and associated near-surface gales behind them (Zhu et al., 2008). The Mongolian cyclone, also known as the Mongolian low pressure, occurs or develops in Mongolia and is often accompanied by fronts, which mostly occur on the central and eastern plateaus of Mongolia on the leeward slopes of the terrain. The variation in the location and intensity of Mongolian cyclones will affect how dust is transported across NC. Here, first, the ERA5 meteorology associated with the 3.15 event is analyzed by focusing on the SLP, temperature, and wind vectors. Fig. $8 \mathrm{~b}$ displays the spatial patterns of the daily mean SLP, temperature at $2 \mathrm{~m}$, and wind vectors at $10 \mathrm{~m}$ on the day before the 3.15 event (March 14). On this day, an exceptionally strong Mongolian cyclone developed on the east side of Mongolia, accompanied by an extremely dense pressure gradient difference between the cyclone and the cold high pressure center on the west side, with the difference in daily average SLP reaching $\sim 50 \mathrm{hPa}$ (Fig. 8b). Induced by such a large pressure gradient difference, northerly gusts exceeding $20 \mathrm{~m} \mathrm{~s}^{-1}$ ensued at the surface near Mongolia (Fig. S5), contributing to the enhancement of dust emissions in Mongolia and driving dust transport to the southeast (Fig. 8a). In terms of timing, such a strong near-surface northerly wind was formed mainly from the late afternoon of March 14 ( 17:00 CST) (Fig. S5d), and it was from that time that a large amount of dust aerosols blown by the gales in Mongolia began to be rapidly transported to Inner Mongolia, China. Next, by analyzing the ERA5 meteorological fields, including the GH, temperature and wind vectors at $700 \mathrm{hPa}$, the focus switches to elucidating how the movement of the Mongolian cyclone during dust episodes controls the dust transport process.

Fig. 9 displays the evolving spatial patterns of the daily mean GH, temperature, and wind vectors at $700 \mathrm{hPa}$ from March 15 to 20 and from March 27 to 29. In general, both SDS events were triggered by an exceptionally strong Mongolian cyclone generated at nearly the same location (along the central and eastern plateau of Inner Mongolia) in conjunction with the surfacelevel cold high-pressure system at the rear, albeit with differences in magnitude and spatial extent of impact. Specifically, on March 15, the Mongolian cyclone was located at the center of $\left(49^{\circ} \mathrm{N}, 125^{\circ} \mathrm{E}\right)$ with a maximum height of $\sim 2740 \mathrm{gpm}$. The northerly winds on the west side of the Mongolian cyclone combined with the northwesterly airflow at high levels will have led to the cold air at the back of the cyclone (west side) moving southwards to create near-surface cooling. Meanwhile, the strong atmospheric pressure difference generated between the cold high pressure (representing cold air) and the Mongolian cyclone (low pressure system) produced windy weather at the back of the cyclone. This configuration of synoptic systems established an unfavorable atmospheric circulation condition for dust emissions from the GD and transported along the direction of cyclone movement, which directly led to surface $\mathrm{PM}_{10}$ concentrations reaching the maximum of this process on March 15. The unfavorable synoptic system persisted on March 16, although it was gradually weakened. By March 17-20, the Mongolian cyclone had weakened further and drifted southeastwards; and meanwhile the northwesterly wind behind the trough continued to drive the dust plume eastwards, affecting most of $\mathrm{NC}$ and the southeast coast.

On March 27, a strong Mongolian cyclone regenerated in the southeastern part of Mongolia along the border with China, with a maximum height of about $2790 \mathrm{gpm}$. Although the difference in GH between the two cyclonic centers was only $50 \mathrm{gpm}$, 
the Mongolian cyclone that developed on March 27 was weaker than the Mongolian cyclone that developed on March 15 in terms of overall intensity and duration, as well as the cold high-pressure system at the rear (Fig. S6), which explains the difference in the amount of dust emissions during these two SDS events. The above analysis indicates that the strength and location of the Mongolian cyclone played a key role in regulating the dust transport during these two events. On March 18 , the Mongolian cyclone drifted further eastwards and the northwesterly winds on the west side of the cyclone transported the dust plume rapidly to the NCP. Up until March 29, the cyclone center was moving out of the Chinese region as a whole and dragged the dust plume to Northeast Asia.

\subsection{Record-breaking dust intensity in March 2021 over the past 20 years}

The magnitude of DOD associated with these two events in March 2021 was a historic one and almost exceeded the climatology from the last 20 years, as recorded in the combined MODIS DOD data retrieved from both Terra and Aqua since 2000. First, a comparison was made between the combined March mean DOD in 2021 (Fig. 10a) and that of the 2001-2021 climatology (Fig. 10b). It should be emphasized that the combined DOD values (Fig. 10) here incorporate information from two sensors at different observation times, which is beneficial for improving the spatial coverage and is also more representative than the DOD values at a single observation time. The results show that the combined DOD values were highly consistent with both Terra-based DOD and Aqua-based DOD in terms of spatial distribution, magnitude, and year-to-year variation (Figs. S7-S10). Furthermore, the combined DOD time series obtained from the two sensor retrievals also utilizes the expanding duration of the target dataset. Therefore, the analyses reported below were carried out based on the combined DOD record from 2001 to 2021.

Clearly, the magnitude of DOD in March 2021 was stronger than in the 20-year climatology, and this remarkable enhancement was mainly located in the GD and its downstream regions, including Ningxia, Gansu, the NCP, and Liaoning. As shown in Fig. 10c, the DOD in March 2020 was more than 0.2-0.8 (depending on the region) higher than the climatology. Among them, the largest positive DOD anomalies were in the Gobi sands and NCP regions. In contrast, a moderate negative anomaly was observed in the core area of the TD, which implies that the two processes had a weak impact on this region. To quantify the magnitude of the impact of these two events in different regions, a regional analysis of MODIS daily and monthly DODs since 2000 was carried out for the entire NC region and its four sub-regions as defined in Fig. 10c: northwest China (NWC), the GD, NCP, and northeast China (NEC). Results from the regional analysis on the daily and monthly scales are shown in Fig. 11 and Fig. 12, respectively. In each region, the daily regional-averaged DOD in March 2021 is highlighted as red dots and lines, while the gray lines depict in detail the evolution of the daily regional-averaged DOD in March for each year during the period of 2000-2020. Clearly, the 3.15 event had the highest or close to highest daily DOD over the past two decades over the entire NC region (March 16, Fig. 11a), the GD (March 15, Fig. 11c), and the NCP (March 18, Fig. 11d). In NWC, the magnitude of DOD is generally determined by the variability of local meteorological factors (mainly surface wind speed). Despite this, the enhanced DOD during the 3.15 event was still relatively high in the last 20 years, which indirectly reflects the wide range of regional impacts of the atmospheric circulation extremes. 
In contrast, although the 3.27 event was weaker than the 3.15 event overall, the former still witnessed the largest or close to largest DOD on the same day in history over the entire NC region (March 28), the GD (March 27), the NCP (March 28), and NEC (March 28). The monthly regional analysis shows that March 2021 was also strongest or second strongest dust month over the past two decades over different study regions, which is attributable to the occurrence of these two dust events with historical levels of intensity in March 2021 (Fig.12). Specifically, in the GD (the entire NC region and NEC), March 2021 had the highest (second highest) DOD in March over the past two decades. In other words, March 2021 was the strongest dust month in these regions in the past 20 years, except for 2010.

The daily DOD anomalies in March 2021 were more prominent when focusing only on the combined period of March 1520 and 27-29 (abbreviated as SDS days, Fig. 13 and Fig. 14). As shown in Fig. 13, the daily composite of SDS days in March 2021 is more than 1.0 higher than the climatology. Moreover, this DOD enhancement covers almost the entire northern region of China except for the northwestern part of Xinjiang, the northeastern part of Inner Mongolia, and the eastern part of LiaoningJilin-Heilongjiang. As expected, the daily composite of SDS days in March 2021 has the highest DOD in the past 20 years over the entire NC region, the GD, and the NCP (Fig. 14). Especially in the GD (the entire NC region and the NCP), the magnitude of daily composited DOD on SDS days is almost twice (1.5 times) as high as the second highest (i.e., March 2010) in history.

\subsection{Anomalous meteorological drivers conducive to dust emissions}

So, what drove the record-breaking dust intensity in March 2021 over the past 20 years? Earlier, atmospheric circulation extremes were identified as the main external driver of these two extreme SDS events (see Section 3.3). Next, however, the internal drivers are explored by focusing on the extent of local meteorological anomalies affecting the surface conditions in the dust source region. Previous studies have revealed that the variability of dust emission intensity in the dust source area of

$405 \mathrm{NC}$ is mainly controlled by several local meteorological factors, such as temperature, PPT and VSW (Kim and Choi, 2015; Wu et al., 2018; Yao et al., 2021). These factors have previously been demonstrated to constrain the intensity of dust emissions and their variability on multiple timescales.

Figs. 15a-d present the meteorological anomalies of two weeks before the 3.15 event with reference to the $2000-2020$ climatology, including the temperature at $2 \mathrm{~m}, \mathrm{SD}, \mathrm{PPT}$, and VSW. Since the two strong SDS processes in March 2021

410 originated from the GD, the annual time series of these meteorological factors averaged over the GD (black box in Fig. S15) were further calculated, as shown in Figs. 15e-h. The results of the 3.27 event are shown in Fig. S11. The ERA5 meteorological analysis indicates that, from the beginning of March 2021, the near-surface temperature in western Inner Mongolia and Mongolia was more than $4.0^{\circ} \mathrm{C}$ warmer than the climatology (Fig. 15a), leading to early melting of snow covering the ground (Fig. 15b). Meanwhile, the dust source areas tended to become drier owing to decreased VSW associated with negative 415 precipitation anomalies (Figs. 15c and d). On the one hand, such a high temperature anomaly made it easier to form a warm low pressure on the ground, the pressure of the Mongolian cyclone was likely to be lower, and the pressure gradient between the cold and high pressure was likely to be larger, which would have been conducive to aggravating gales. On the other hand, 
such a dry environment would have made the surface of the sand source looser, which would have favored an enhancement of dust emissions driven by the strong winds. Although the magnitude of these local meteorological anomalies was moderate before the 3.27 event (Fig. S11), their overall pattern did not change significantly, which to some extent created favorable conditions for the 3.27 event to occur.

The time series of regional-averaged local meteorological drivers suggest that, while an exceptionally strong Mongolian cyclone triggered dust emissions from the GD, intensified temperatures $\left(4.6^{\circ} \mathrm{C}\right.$ warmer than the climatology and the strongest in the past 22 years for March 1-14) led to the melting of snow (1.85 mm lower than the climatology and the lowest in the past 22 years $)$, accompanied by decreased PPT $(0.007 \mathrm{~mm}$ lower than the climatology and the second lowest in the past 22 years) and VSW $\left(0.011 \mathrm{~m}^{3} \mathrm{~m}^{-3}\right.$ lower than the climatology and the third lowest in the past 22 years) systematically contributed to the further enhancement of dust emissions during the 3.15 event. For the 3.27 event, positive anomalies significantly above or below the climatology were observed for all four meteorological factors (Fig. S11).

\section{Conclusions and implications}

In March 2021, two unexpected mega SDS events (referred to here as the "3.15" and "3.27" events), separated by only a week, invaded most of NC, significantly worsening the air quality, threatening people's health and disrupting economic and social activities. In this study, a long-term (2000-2021) MODIS-retrieved DOD dataset and a variety of multiple satellite and ground-based observations combined with atmospheric reanalysis data were used to describe the three-dimensional evolution features of the massive dust aerosol intrusion into NC during these two events. Meanwhile, the local meteorological drivers behind the occurrence of these two SDS events were initially explored.

During both events, the invasion of dust plumes raised the $\mathrm{PM}_{10}$ concentration to extremely hazardous levels in most of $\mathrm{NC}$, with a maximum daily mean $\mathrm{PM}_{10}$ concentration of $7058 \mu \mathrm{g} \mathrm{m}^{-3}\left(2670 \mu \mathrm{g} \mathrm{m}^{-3}\right)$ recorded on March 15 (28). Even more exaggerated is that on March 15-16 and March 27-28, the instantaneous surface $\mathrm{PM}_{10}$ concentrations exceeded the monitoring threshold of $9985 \mu \mathrm{g} \mathrm{m}^{-3}$ at multiple individual sites. Analysis of MERRA-2 dust emissions suggested that the two SDS processes originated in the GD across southern Mongolia and NC. Specifically, mineral dust aerosols from the GD in Mongolia were first blown up and subsequently mixed with those emitted from the GD in NC, and were continually transported to the downstream region. During the dust transport episode of the 3.15 event, the dust plume with an AEC greater than $0.05 \mathrm{~km}^{-1}$ was lifted to an altitude of $4-8 \mathrm{~km}$, and its range of impact extended from the dust source to the eastern coast of China. In contrast, the lifting altitude of the dust plume during the 3.27 event was lower than that during 3.15 event, with the top of the dust plume (AEC $>0.05 \mathrm{~km}^{-1}$ ) at about $5 \mathrm{~km}$. The difference in lifting altitude of the dust plume during these two dust transport processes was also confirmed by ground-based lidar observations in Inner Mongolia. For these two mega SDS events, the regional-averaged DOD in the dust source (here, the GD) and its downstream (i.e., the NCP) broke the MODIS record in the past 20 years for the same period (i.e., the combined period of March 15-20 and 27-29) in history, with the daily mean DOD exceeding 2.0 over the GD and NCP. On a monthly average scale, the strong impacts attributed to these two processes directly 
led to March 2021 being registered as the strongest DOD month in the past decade across the entire NC region, even in the past two decades, second only to March 2010 (Bian et al., 2011; Tan et al., 2017).

Analysis of ERA5 meteorological data suggested that these two mega SDS events were associated with both atmospheric circulation extremes and local meteorological anomalies that favored enhanced dust emissions in the GD. Firstly, both SDS events were caused by strong surface wind speeds triggered by an exceptionally strong Mongolian cyclone generated at nearly the same location (along the central and eastern plateau of Inner Mongolia) in conjunction with the surface-level cold highpressure system at the rear. Secondly, although anomalies in surface wind speed provided the dynamical conditions for dust emissions, the early melting of spring snow caused by near-surface temperature anomalies over dust source regions, together with the negative soil moisture anomalies induced by decreased precipitation, formed drier and barer soil surfaces, which systematically provided the material conditions for the SDS events to occur. Although the atmospheric circulation anomalies in both events were similar to the typical circulation patterns that facilitate the occurrence of spring SDS events in NC (Zhu et al., 2008), the degree of surface dryness/bareness and wind anomalies were astounding, emphasizing the substantial contribution of the joint effects of the surface condition and atmospheric circulation anomalies to the occurrence of both extreme SDS events.

Against the backdrop of the continued absence of strong SDS events in NC in almost a decade (An et al., 2018; Wang et al., 2018; Liu et al., 2020; Yao et al., 2021), this unexpected resurgence of two mega SDS events has raised potential concern as to whether such extreme SDS events will occur frequently in the future or whether a fresh active cycle of dust will begin. Currently, there is no consensus on whether future dust aerosol emissions in NC will increase or decrease. Some studies suggest that dust emissions and the occurrence frequency of SDS events in NC may continually decrease in the future (Tegen et al., 2004; Liu et al., 2020), and they attribute this to enhanced Arctic amplification under the future climate (Zhang et al. 2019; Liu et al., 2020) accompanied by reduced temperature gradients at mid and high latitudes leading to reduced westerly winds, increased precipitation and enhanced leaf area index (Zong et al., 2021), which is not conducive to dust emissions. However, other studies have also found that, under a scenario of continued global warming, land degradation and desertification in arid areas of East Asia will be aggravated, and the inner region of East Asia (covering the GD) is likely to become drier and hotter (Huang et al., 2016; Zhang et al., 2020), which will provide favorable surface conditions for increases in future dust emissions.

475 Given the importance of Asian dust in regional climate, ecosystems, environment, air quality, and public health, further exploration is still needed in the future regarding how dust aerosols may evolve in NC. The present study highlights that improving the projection of large-scale circulation anomalies and surface conditions will be the key determinant in terms of confidence in climate models to predict whether dust aerosols in $\mathrm{NC}$ will increase or decrease in the future.

Data availability. All data or products used in this study were obtained from various publicly available sources: the MODIS aerosol optical property data (MOD04_L2 and MYD04_L2) and OMPS-NPP L2 UVAI product (OMPS_NPP_NMMIEAI_L2) were obtained from Earthdata Search (https://search.earthdata.nasa.gov/search), a web application developed by NASA's Earth Observing System Data and Information System (EOSDIS). The CALIOP aerosol extinction profile product 
(CAL_LID_L2_05kmAPro-Standard-V4-21) was obtained from the NASA Langley Atmospheric Science Data Center (ASDC) by CALIPSO's search and subsetting web application (https://subset.larc.nasa.gov/calipso/login.php). The Suomi NPP VIIRS images were produced by the Worldview tool from NASA's EOSDIS (https://worldview.earthdata.nasa.gov/). The MERRA2 aerosol reanalysis data are available via the Goddard Earth Sciences Data and Information Services Center (GES DISC) (https://earthdata.nasa.gov/eosdis/daacs/gesdisc). The ERA5 reanalysis data from ECMWF can be accessed at the Copernicus Climate Data Store (CDS) (https://cds.climate.copernicus.eu/cdsapp\#!/home). The hourly $\mathrm{PM}_{10}$ data were downloaded from CNEMC (http://www.cnemc.cn). The ground-based lidar data were provided courtesy of AD-Net (https://wwwlidar.nies.go.jp/AD-Net).

Author contributions. $\mathrm{HC}$ and $\mathrm{KG}$ designed the study. KG performed the data analysis with contributions from all coauthors; KG and WY prepared and drafted the paper with help from HC and LA; LL, YZ, HZ, LZ, JZ, YW, and XZ provided constructive suggestions on this study.

Competing Interests. The authors declare that they have no conflict of interest.

Acknowledgements. This research has been supported by the National Key R\&D Program Pilot Projects of China (grant no. 2016YFA0601901), National Science Fund for Distinguished Young Scholars (grant no. 41825011), the National Natural Science Foundation of China project (grant nos. 42030608 and 41905121), and the Basic Research Fund of CAMS (No. 2021Y001).

\section{References}

An, L., Che, H., Xue, M., Zhang, T., Wang, H., Wang, Y., Zhou, C., Zhao, H., Gui, K., Zheng, Y., Sun, T., Liang, Y., Sun, E., Zhang, H. and Zhang, X.: Temporal and spatial variations in sand and dust storm events in East Asia from 2007 to 2016 : Relationships with surface conditions and climate change, Sci. Total Environ., 633, 452-462, doi:10.1016/j.scitotenv.2018.03.068, 2018.

Anderson, T. L., Wu, Y., Chu, D. A., Schmid, B., Redemann, J. and Dubovik, O.: Testing the MODIS satellite retrieval of aerosol fine-mode fraction, J. Geophys. Res. D Atmos., 110(18), 1-16, doi:10.1029/2005JD005978, 2005.

Bian, H., Tie, X., Cao, J., Ying, Z., Han, S. and Xue, Y.: Analysis of a severe dust storm event over China: Application of the WRF-dust model, Aerosol Air Qual. Res., 11(4), 419-428, doi:10.4209/aaqr.2011.04.0053, 2011.

Buchard, V., Randles, C. A., da Silva, A. M., Darmenov, A., Colarco, P. R., Govindaraju, R., Ferrare, R., Hair, J., Beyersdorf, A. J., Ziemba, L. D. and Yu, H.: The MERRA-2 Aerosol Reanalysis, 1980 Onward. Part I: System Description and Data Assimilation Evaluation, J. Clim., 30(17), 6851-6872, doi:10.1175/JCLI-D-16-0613.1, 2017. 
Chen, C., Park, T., Wang, X., Piao, S., Xu, B., Chaturvedi, R. K., Fuchs, R., Brovkin, V., Ciais, P., Fensholt, R., Tømmervik, H., Bala, G., Zhu, Z., Nemani, R. R. and Myneni, R. B.: China and India lead in greening of the world through land-use management, Nat. Sustain., 2(2), 122-129, doi:10.1038/s41893-019-0220-7, 2019.

Chen, S., Huang, J., Qian, Y., Zhao, C., Kang, L., Yang, B., Wang, Y., Liu, Y., Yuan, T., Wang, T., Ma, X. and Zhang, G.: An overview of mineral dust modeling over East Asia, J. Meteorol. Res., 31(4), 633-653, doi:10.1007/s13351-017-61422, 2017a.

Chen, S. Y., Huang, J. P., Li, J. X., Jia, R., Jiang, N. X., Kang, L. T., Ma, X. J. and Xie, T. T.: Comparison of dust emissions, transport, and deposition between the Taklimakan Desert and Gobi Desert from 2007 to 2011, Sci. China Earth Sci., 60(7), 1338-1355, doi:10.1007/s11430-016-9051-0, 2017b.

Duncan Fairlie, T., Jacob, D. J. and Park, R. J.: The impact of transpacific transport of mineral dust in the United States, Atmos. Environ., 41(6), 1251-1266, doi:10.1016/j.atmosenv.2006.09.048, 2007.

Ginoux, P., Chin, M., Tegen, I., Prospero, J. M., Holben, B., Dubovik, O. and Lin, S. J.: Sources and distributions of dust aerosols simulated with the GOCART model, J. Geophys. Res. Atmos., 106(D17), 20255-20273, doi:10.1029/2000JD000053, 2001.

Gkikas, A., Proestakis, E., Amiridis, V., Kazadzis, S., Di Tomaso, E., Tsekeri, A., Marinou, E., Hatzianastassiou, N. and Pérez García-Pando, C.: ModIs Dust AeroSol (MIDAS): a global fine-resolution dust optical depth data set, Atmos. Meas. Tech., 14(1), 309-334, doi:10.5194/amt-14-309-2021, 2021.

Gong, S. L., Zhang, X. Y., Zhao, T. L. and Barrie, L. A.: Sensitivity of Asian dust storm to natural and anthropogenic factors, Geophys. Res. Lett., 31(7), 2-5, doi:10.1029/2004GL019502, 2004.

Gong, S. L., Zhang, X. Y., Zhao, T. L., Zhang, X. B., Barrie, L. A., Mckendry, I. G. and Zhao, C. S.: A simulated climatology of Asian dust aerosol and its trans-pacific transport. Part II: Interannual variability and climate connections, J. Clim., 19(1), 104-122, doi:10.1175/JCLI3606.1, 2006.

Gui, K., Che, H., Zheng, Y., Zhao, H., Yao, W., Li, L., Zhang, L., Wang, H., Wang, Y. and Zhang, X.: Three-dimensional climatology, trends, and meteorological drivers of global and regional tropospheric type-dependent aerosols: insights from 13 years (2007-2019) of CALIOP observations, Atmos. Chem. Phys., 21, 15309-15336, doi:10.5194/acp-2115309-2021, 2021.

Hersbach, H., Bell, B., Berrisford, P., Hirahara, S., Horányi, A., Muñoz-Sabater, J., Nicolas, J., Peubey, C., Radu, R., Schepers, D., Simmons, A., Soci, C., Abdalla, S., Abellan, X., Balsamo, G., Bechtold, P., Biavati, G., Bidlot, J., Bonavita, M., De Chiara, G., Dahlgren, P., Dee, D., Diamantakis, M., Dragani, R., Flemming, J., Forbes, R., Fuentes, M., Geer, A., Haimberger, L., Healy, S., Hogan, R. J., Hólm, E., Janisková, M., Keeley, S., Laloyaux, P., Lopez, P., Lupu, C., Radnoti, G., de Rosnay, P., Rozum, I., Vamborg, F., Villaume, S. and Thépaut, J. N.: The ERA5 global reanalysis, Q. J. R. Meteorol. Soc., 146(730), 1999-2049, doi:10.1002/qj.3803, 2020. 
Hillger, D., Kopp, T., Lee, T., Lindsey, D., Seaman, C., Miller, S., Solbrig, J., Kidder, S., Bachmeier, S., Jasmin, T. and Rink, T.: First-light imagery from Suomi NPP VIIRS, Bull. Am. Meteorol. Soc., 94(7), 1019-1029, doi:10.1175/BAMS-D-1200097.1, 2013.

Huang, J., Yu, H., Guan, X., Wang, G. and Guo, R.: Accelerated dryland expansion under climate change, Nat. Clim. Chang., 6(2), 166-171, doi:10.1038/nclimate2837, 2016.

Kablick, G. P., Allen, D. R., Fromm, M. D. and Nedoluha, G. E.: Australian PyroCb Smoke Generates Synoptic-Scale Stratospheric Anticyclones, Geophys. Res. Lett., 47(13), doi:10.1029/2020GL088101, 2020.

Kim, H. and Choi, M.: Impact of soil moisture on dust outbreaks in East Asia: Using satellite and assimilation data, Geophys. Res. Lett., 42(8), 2789-2796, doi:10.1002/2015GL063325, 2015.

Kok, J., Adebiyi, A., Albani, S., Balkanski, Y., Checa-Garcia, R., Chin, M., Colarco, P., Hamilton, D. S., Huang, Y., Ito, A., Klose, M., Leung, D., Li, L., Mahowald, N., Miller, R., Obiso, V., Pérez García-Pando, C., Rocha-Lima, A., Wan, J. and Whicker, C.: Improved representation of the global dust cycle using observational constraints on dust properties and abundance, Atmos. Chem. Phys., 1-45, doi:10.5194/acp-2020-1131, 2020.

Kok, J. F., Ridley, D. A., Zhou, Q., Miller, R. L., Zhao, C., Heald, C. L., Ward, D. S., Albani, S. and Haustein, K.: Smaller desert dust cooling effect estimated from analysis of dust size and abundance, Nat. Geosci., 10(4), 274-278, doi:10.1038/ngeo2912, 2017.

Kok, J. F., Adebiyi, A. A., Albani, S., Balkanski, Y., Checa-Garcia, R., Chin, M., Colarco, P. R., Hamilton, D. S., Huang, Y., Ito, A., Klose, M., Li, L., Mahowald, N. M., Miller, R. L., Obiso, V., Pérez García-Pando, C., Rocha-Lima, A. and Wan, J. S.: Contribution of the world's main dust source regions to the global cycle of desert dust, Atmos. Chem. Phys., 21(10), 8169-8193, doi:10.5194/acp-21-8169-2021, 2021.

Liang, P., Chen, B., Yang, X., Liu, Q., Li, A., Mackenzie, L. and Zhang, D.: Revealing the dust transport processes of the 2021 mega dust storm event in northern China, Sci. Bull., doi:10.1016/j.scib.2021.08.014, 2021.

Liu, J., Wu, D., Liu, G., Mao, R., Chen, S., Ji, M., Fu, P., Sun, Y., Pan, X., Jin, H., Zhou, Y. and Wang, X.: Impact of Arctic amplification on declining spring dust events in East Asia, Clim. Dyn., 54(3-4), 1913-1935, doi:10.1007/s00382-01905094-4, 2020.

Logothetis, S.-A., Salamalikis, V., Gkikas, A., Kazadzis, S., Amiridis, V., and Kazantzidis, A.: 15-year variability of desert dust optical depth on global and regional scales, Atmos. Chem. Phys. Discuss. [preprint], https://doi.org/10.5194/acp2021-418, in review, 2021.

Pu, B. and Ginoux, P.: The impact of the Pacific Decadal Oscillation on springtime dust activity in Syria, impact Pacific Decad. Oscil. springtime dust Act. Syria, 16, 13431-13448, doi:10.5194/acp-16-13431-2016, 2016.

Pu, B. and Ginoux, P.: How reliable are CMIP5 models in simulating dust optical depth?, Atmos. Chem. Phys., 18(16), 1249112510, doi:10.5194/acp-18-12491-2018, 2018.

$575 \mathrm{Pu}, \mathrm{B}$. and Jin, Q.: A record-breaking trans-Atlantic African dust plume associated with atmospheric circulation extremes in June 2020, Bull. Am. Meteorol. Soc., 1-41, doi:10.1175/bams-d-21-0014.1, 2021. 
Rodríguez, S., Alastuey, A. and Querol, X.: A review of methods for long term in situ characterization of aerosol dust, Aeolian Res., 6, 55-74, doi:10.1016/j.aeolia.2012.07.004, 2012.

Rosenfeld, D., Rudich, Y. and Lahav, R.: Desert dust suppressing precipitation: A possible desertification feedback loop, Proc. Natl. Acad. Sci. U. S. A., 98(11), 5975-5980, doi:10.1073/pnas.101122798, 2001.

Sayer, A. M., Hsu, N. C., Lee, J., Kim, W. V. and Dutcher, S. T.: Validation, Stability, and Consistency of MODIS Collection 6.1 and VIIRS Version 1 Deep Blue Aerosol Data Over Land, J. Geophys. Res. Atmos., 124(8), 4658-4688, doi:10.1029/2018JD029598, 2019.

Shimizu, A., Sugimoto, N., Matsui, I., Arao, K., Uno, I., Murayama, T., Kagawa, N., Aoki, K., Uchiyama, A. and Yamazaki, A. A.: Continuous observations of Asian dust and other aerosols by polarization lidars in China and Japan during ACEAsia, J. Geophys. Res. D Atmos., 109(19), doi:10.1029/2002JD003253, 2004.

Shimizu, A., Sugimoto, N. and Matsui, I.: Detailed description of data processing system for lidar network in East Asia, 25th Int. Laser Radar Conf., (October 2014), 911-913 [online] Available from: http://wwwlidar.nies.go.jp/ cml/English/ILRC_25_Shimizu.pdf, 2010.

Song, Q., Zhang, Z., Yu, H., Ginoux, P. and Shen, J.: Global Dust Optical Depth Climatology Derived from CALIOP and MODIS Aerosol Retrievals on Decadal Time Scales: Regional and Interannual Variability, Atmos. Chem. Phys. Discuss., 1-57, doi:10.5194/acp-2021-1, 2021.

Sugimoto, N., Matsui, I., Shimizu, A., Nishizawa, T., Hara, Y., Xie, C., Uno, I., Yumimoto, K., Wang, Z. and Yoon, S. -C.: Lidar network observations of tropospheric aerosols, Lidar Remote Sens. Environ. Monit. IX, 7153(December), 71530A, doi:10.1117/12.806540, 2008.

Tan, S. C., Li, J., Che, H., Chen, B. and Wang, H.: Transport of East Asian dust storms to the marginal seas of China and the southern North Pacific in spring 2010, Atmos. Environ., 148, 316-328, doi:10.1016/j.atmosenv.2016.10.054, 2017.

Tao, M., Gui, L., Li, R., Wang, L., Liang, S., Li, Q., Wang, L., Yu, C. and Chen, L.: Tracking prevailing dust aerosol over the air pollution in central China with integrated satellite and ground observations, Atmos. Environ., 253(388), 118369, doi:10.1016/j.atmosenv.2021.118369, 2021.

Tegen, I., Werner, M., Harrison, S. P. and Kohfeld, K. E.: Relative importance of climate and land use in determining present and future global soil dust emission, Geophys. Res. Lett., 31(5), doi:10.1029/2003gl019216, 2004.

Wang, X., Liu, J., Che, H., Ji, F. and Liu, J.: Spatial and temporal evolution of natural and anthropogenic dust events over northern China, Sci. Rep., 8(1), doi:10.1038/s41598-018-20382-5, 2018.

WHO: WHO global air quality guidelines: particulate matter $\left(\mathrm{PM}_{2.5}\right.$ and $\left.\mathrm{PM}_{10}\right)$, ozone, nitrogen dioxide, sulfur dioxide and carbon monoxide: executive summary., 2021.

Winker, D. M., Pelon, J., Coakley, J. A., Ackerman, S. A., Charlson, R. J., Colarco, P. R., Flamant, P., Fu, Q., Hoff, R. M., Kittaka, C., Kubar, T. L., Le Treut, H., McCormick, M. P., Mégie, G., Poole, L., Powell, K., Trepte, K., Vaughan, M. A. and Wielicki, B. A.: The Calipso Mission: A Global 3D View of Aerosols and Clouds, Bull. Am. Meteorol. Soc., 91(9), 1211-1229, doi:10.1175/2010BAMS3009.1, 2010. 
Wu, C., Lin, Z., Liu, X., Li, Y., Lu, Z. and Wu, M.: Can Climate Models Reproduce the Decadal Change of Dust Aerosol in East Asia?, Geophys. Res. Lett., 45(18), 9953-9962, doi:10.1029/2018GL079376, 2018.

Wu, M., Liu, X., Yu, H., Wang, H., Shi, Y., Yang, K., Darmenov, A., Wu, C., Wang, Z., Luo, T., Feng, Y. and Ke, Z.: Understanding processes that control dust spatial distributions with global climate models and satellite observations, Atmos. Chem. Phys., 20(22), 13835-13855, doi:10.5194/acp-20-13835-2020, 2020.

$\mathrm{Wu}, \mathrm{Y} .$, Wen, B. and Guo, Y.: Comment Sand and dust storms in Asia : a call for global cooperation on climate change, , 5196(April), doi:10.1016/S2542-5196(21)00082-6, 2021.

Yao, W., Che, H., Gui, K., Wang, Y. and Zhang, X.: Can MERRA-2 Reanalysis Data Reproduce the Three-Dimensional Evolution Characteristics of a Typical Dust Process in East Asia? A Case Study of the Dust Event in May 2017, Remote Sens., doi:10.3390/rs12060902, 2020.

Yao, W., Gui, K., Wang, Y., Che, H. and Zhang, X.: Identifying the dominant local factors of 2000-2019 changes in dust loading over East Asia, Sci. Total Environ., 777, 146064, doi:10.1016/j.scitotenv.2021.146064, 2021.

Yin, Z., Wan, Y., Zhang, Y. and Wang, H.: Why super sandstorm 2021 in North China, Natl. Sci. Rev., doi:10.1093/nsr/nwab165, 2021.

625 Yu, H., Tan, Q., Zhou, L., Zhou, Y., Bian, H., Chin, M., Ryder, C. L., Levy, R. C., Pradhan, Y., Shi, Y., Song, Q., Zhang, Z., Colarco, P. R., Kim, D., Remer, L. A., Yuan, T., Mayol-Bracero, O. and Holben, B. N.: Observation and modeling of the historic "godzilla" African dust intrusion into the Caribbean Basin and the southern US in June 2020, Atmos. Chem. Phys., 21(16), 12359-12383, doi:10.5194/acp-21-12359-2021, 2021.

Zhang, P., Jeong, J. H., Yoon, J. H., Kim, H., Simon Wang, S. Y., Linderholm, H. W., Fang, K., Wu, X. and Chen, D.: Abrupt shift to hotter and drier climate over inner East Asia beyond the tipping point, Science (80-. )., 370(6520), 1095-1099, doi:10.1126/science.abb3368, 2020.

Zhang, X. Y., Gong, S. L., Zhao, T. L., Arimoto, R., Wang, Y. Q. and Zhou, Z. J.: Sources of Asian dust and role of climate change versus desertification in Asian dust emission, Geophys. Res. Lett., 30(24), doi:10.1029/2003GL018206, $2003 \mathrm{a}$.

Zhang, X. Y., Gong, S. L., Shen, Z. X., Mei, F. M., Xi, X. X., Liu, L. C., Zhou, Z. J., Wang, D., Wang, Y. Q. and Cheng, Y.: Characterization of soil dust aerosol in China and its transport and distribution during 2001 ACE-Asia: 1. Network observations, J. Geophys. Res. Atmos., 108(9), 1-13, doi:10.1029/2002jd002632, 2003b.

Zhao, A., Ryder, C. L., and Wilcox, L. J.: How well do the CMIP6 models simulate dust aerosols?, Atmos. Chem. Phys. Discuss. [preprint], https://doi.org/10.5194/acp-2021-578, in review, 2021.

Zhao, T. L., Gong, S. L., Zhang, X. Y. and Jaffe, D. A.: Asian dust storm influence on North American ambient PM levels: Observational evidence and controlling factors, Atmos. Chem. Phys., 8(10), 2717-2728, doi:10.5194/acp-8-2717-2008, 2008.

Zhu, C., Wang, B. and Qian, W.: Why do dust storms decrease in northern China concurrently with the recent global warming?, Geophys. Res. Lett., 35(18), doi:10.1029/2008GL034886, 2008. 
https://doi.org/10.5194/acp-2021-933

Preprint. Discussion started: 1 December 2021

(C) Author(s) 2021. CC BY 4.0 License.

(c) (i)

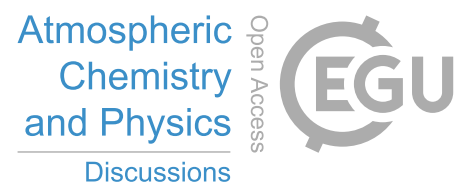

Zong, Q., Mao, R., Gong, D. Y., Wu, C., Pu, B., Feng, X. and Sun, Y.: Changes in Dust Activity in Spring over East Asia 645 under a Global Warming Scenario, Asia-Pacific J. Atmos. Sci., doi:10.1007/s13143-021-00224-7, 2021. 

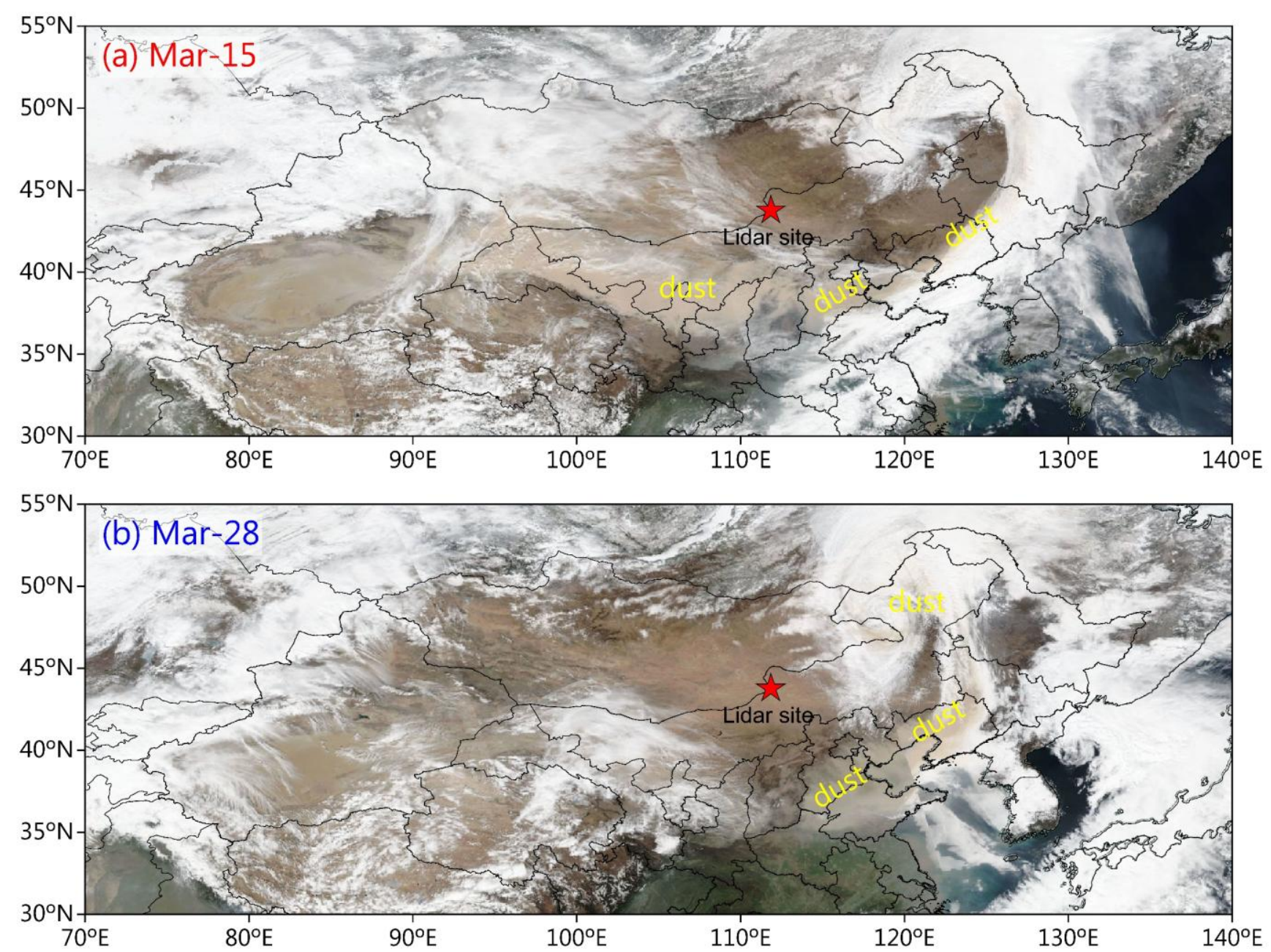

Figure 1: True-color panoramic stitching image of dust plumes above the Earth's surface captured by the VIIRS instrument aboard Suomi NPP on (a) March 15 and (b) March 28, 2021 (https://worldview.earthdata.nasa.gov/). The location of the AD- 
https://doi.org/10.5194/acp-2021-933

Preprint. Discussion started: 1 December 2021

(C) Author(s) 2021. CC BY 4.0 License.
Atmospheric

Chemistry

and Physics

Discussions

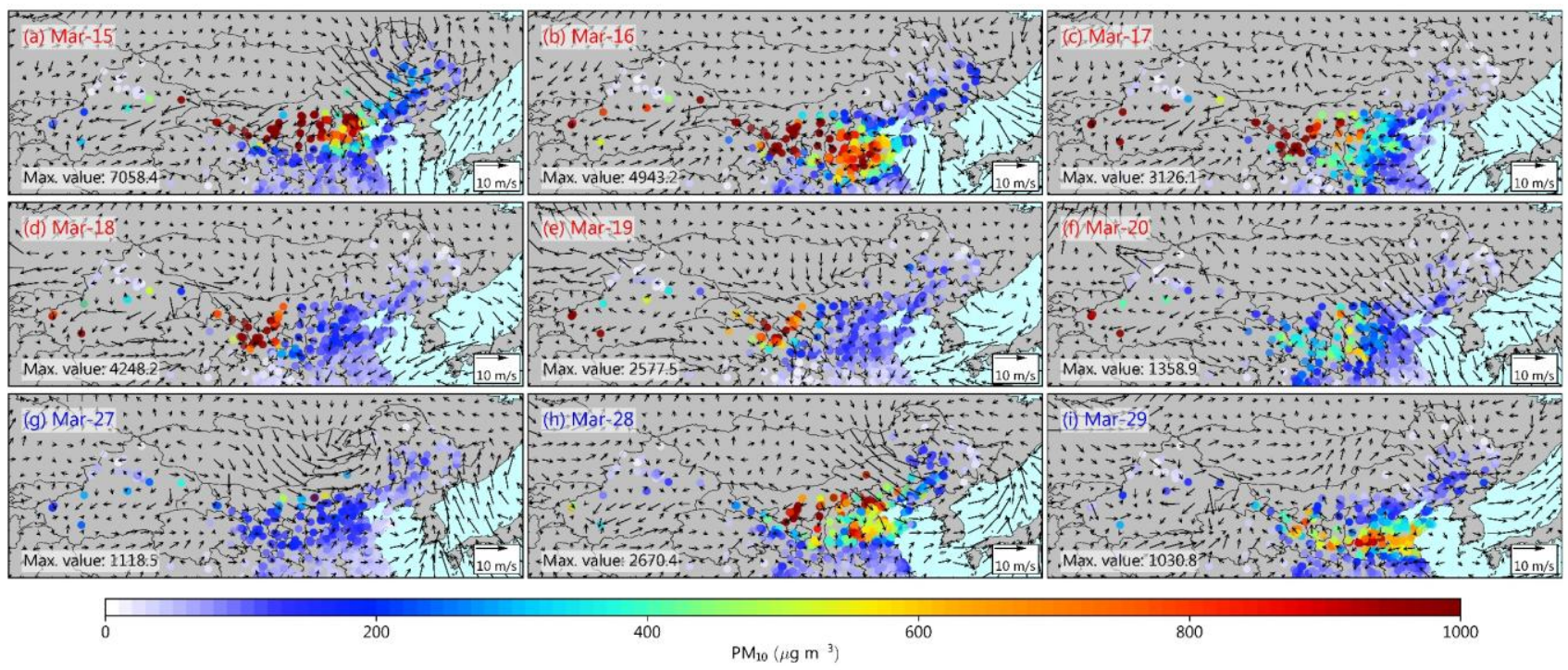

Figure 2: Evolution of observed daily mean PM10 concentrations during (a-f) the 3.15 SDS event (March 15-20, 2021) and (g-i) the 3.27 SDS event (March 27-29, 2021), respectively. Overlaid on the PM10 are the ERA5 wind vectors at $10 \mathrm{~m}$. The single-site maximum values of daily mean $\mathrm{PM}_{10}$ concentrations are marked in the lower-left of each panel. 
(a) Aerosol extinction coefficient at $532 \mathrm{~nm}$

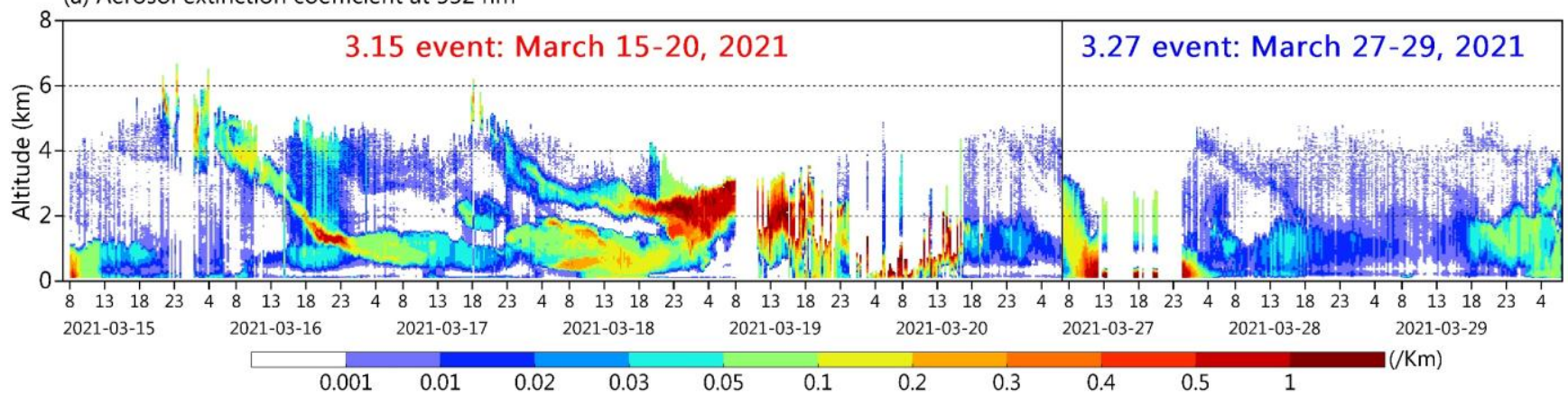

(b) Attenuated backscatter coefficient at $532 \mathrm{~nm}$

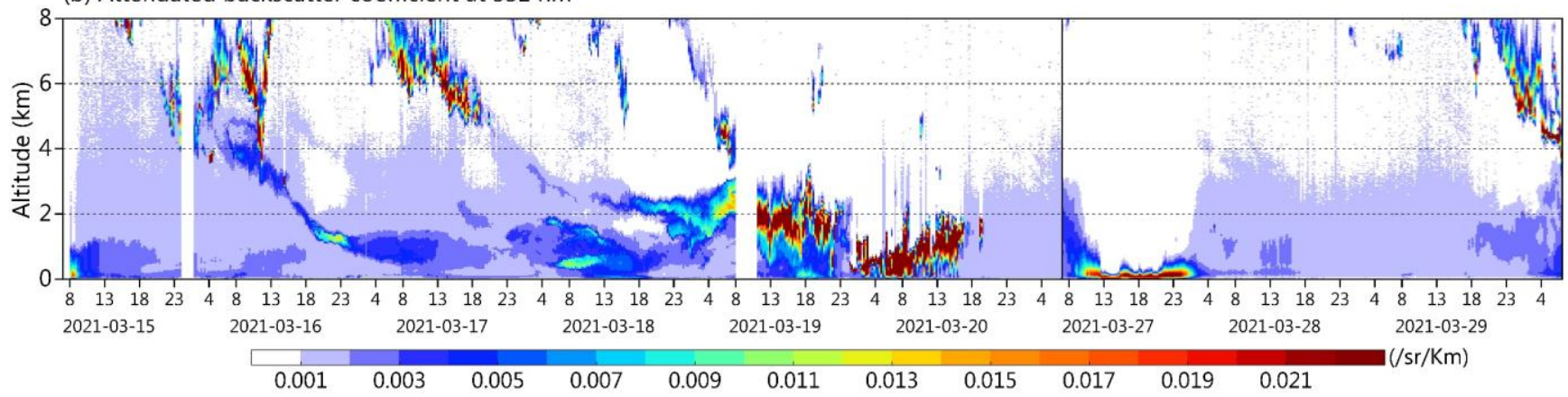

(c) Volume depolarization raito at $532 \mathrm{~nm}$

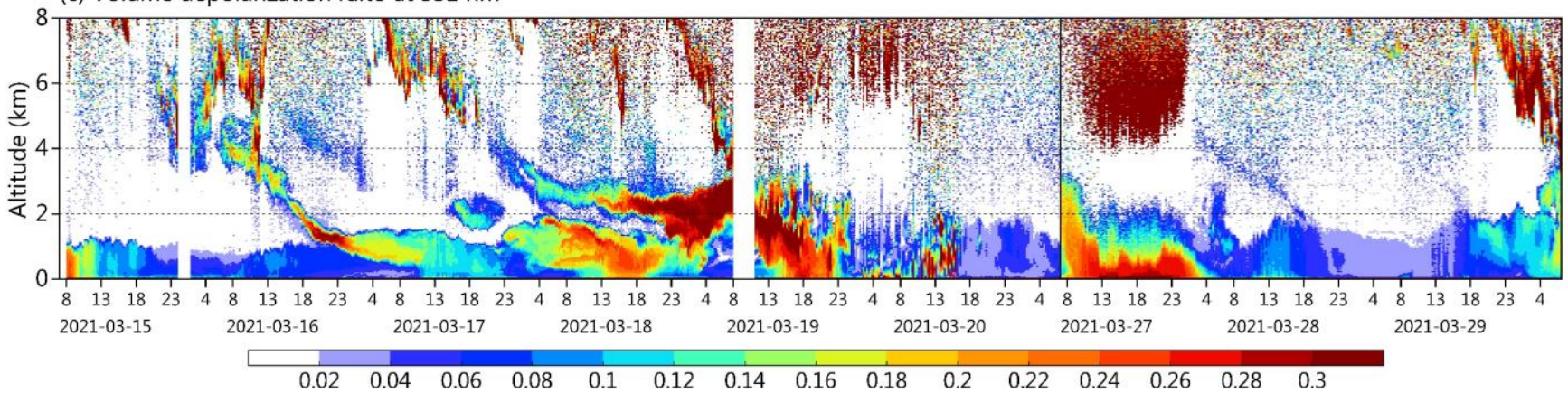

Figure 3: Time-height evolution of aerosol optical properties at $532 \mathrm{~nm}$ as observed by ground-based Lidar (location of the site shown in Fig. 1) during the 3.15 and 3.27 events: (a) aerosol extinction coefficient $\left(\mathrm{km}^{-1}\right)$; (b) attenuated backscatter coefficient $\left(\mathrm{sr}^{-1} \mathrm{~km}^{-1}\right)$; and (c) volume depolarization ratio. 
https://doi.org/10.5194/acp-2021-933

Preprint. Discussion started: 1 December 2021

(c) Author(s) 2021. CC BY 4.0 License.

(c) (i)

Atmospheric

Chemistry and Physics

Discussions

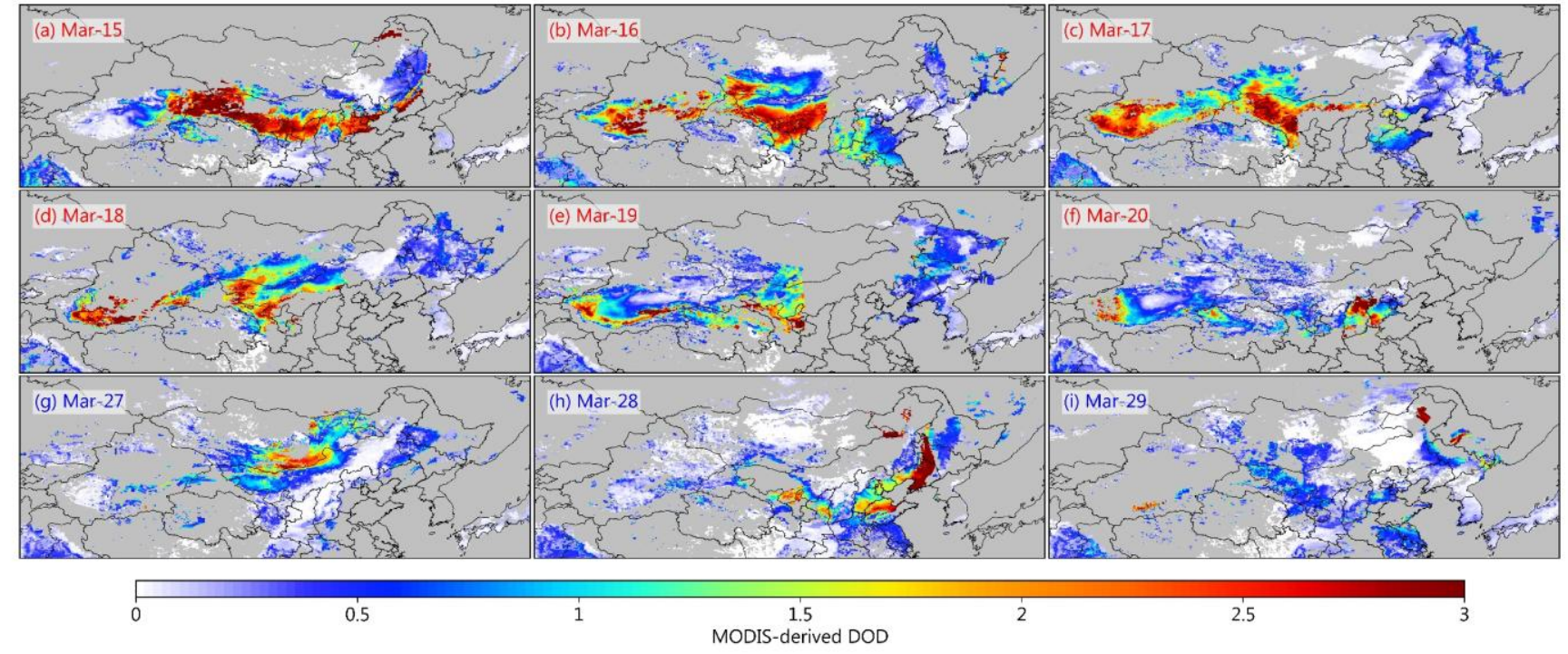

Figure 4: Evolution of Aqua and Terra combined daily mean DOD during (a-f) the 3.15 event and (g-i) the 3.27 event. 


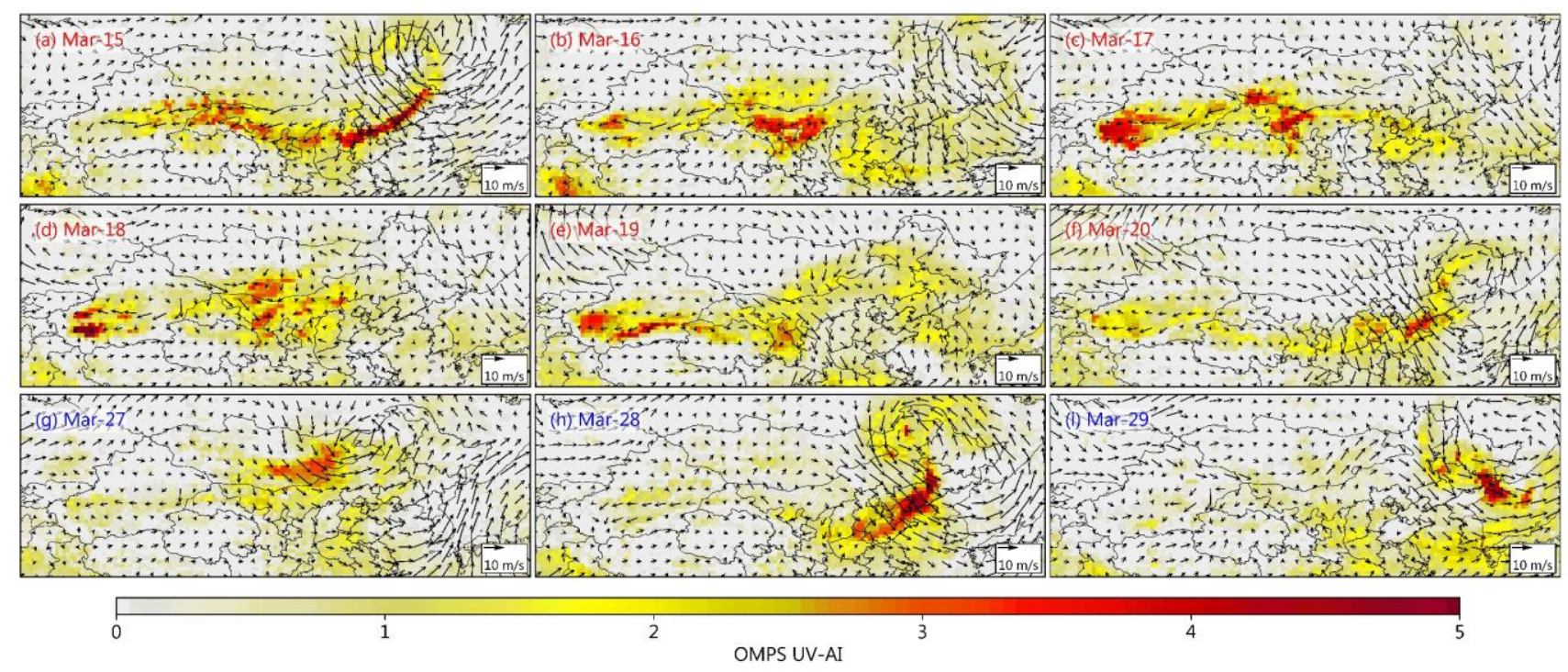

Figure 5: Evolution of dust plume intensity as revealed by the OMPS UVAI (Ultraviolet Aerosol Index; shading) during (a-f) the 3.15 event and ( $\mathrm{g}-\mathrm{i}$ ) the 3.27 event. Overlaid on the UVAI is the ERA5 daily mean wind vectors at $850 \mathrm{hPa}$. 

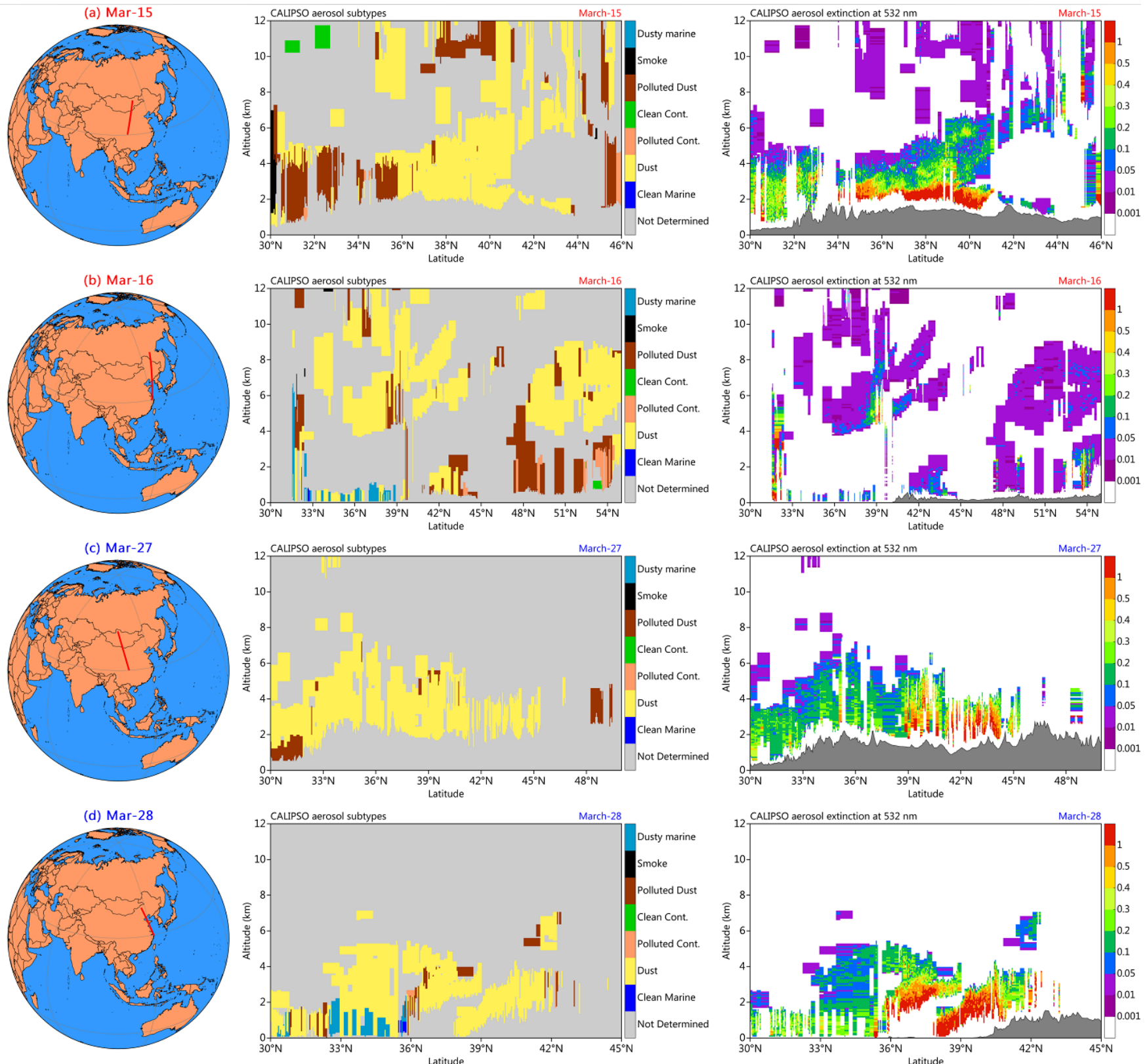

Figure 6: CALIOP/CALIPSO snapshots of dust plumes for (a) March 15, (b) March 16, (c) March 27, and (d) March 28, 2021. The first column presents the CALIPSO tracks (red lines), the second column shows the aerosol subtypes categorized by the gray filled line. 
https://doi.org/10.5194/acp-2021-933

Preprint. Discussion started: 1 December 2021

(c) Author(s) 2021. CC BY 4.0 License.

Atmospheric

Chemistry

(c) (i)

and Physics

Discussions

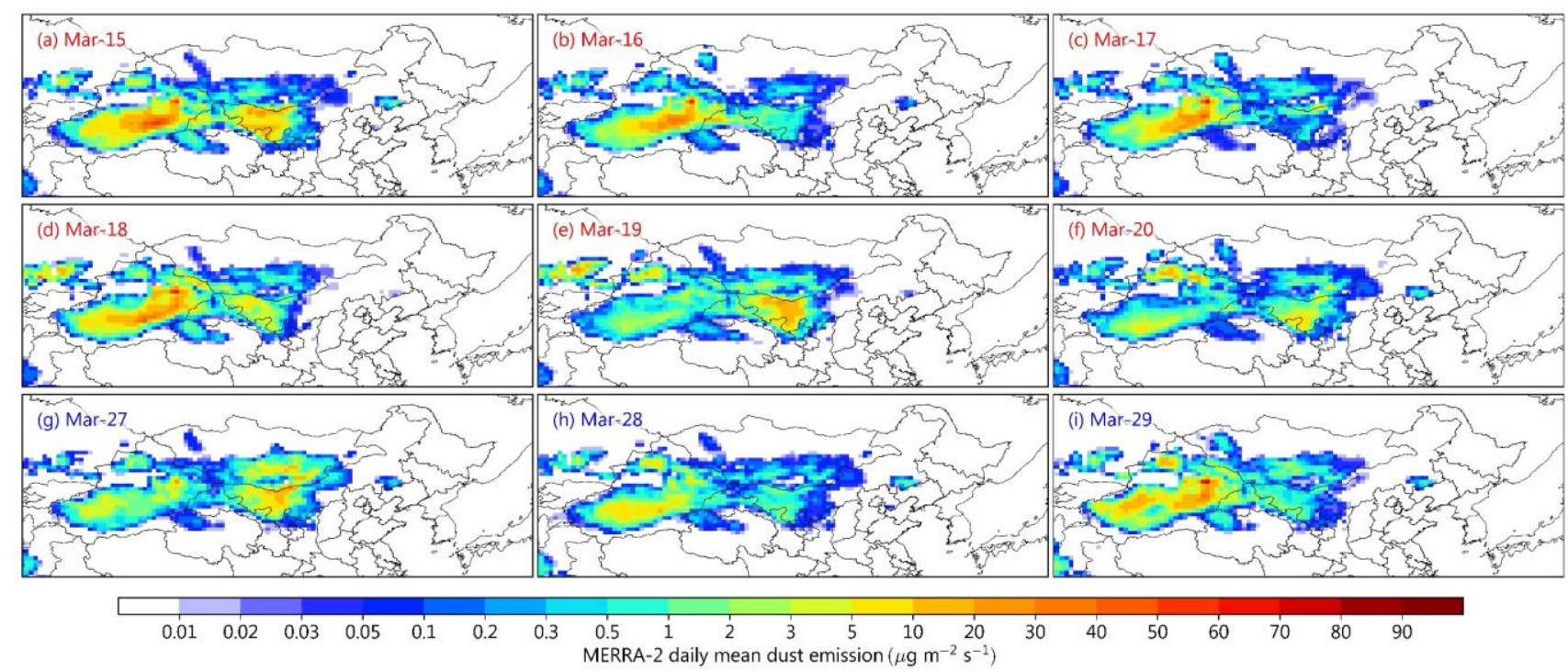

Figure 7: Evolution of MERRA-2 daily mean dust emissions for all size bins during (a-f) the 3.15 event and (g-i) the 3.27 event. 

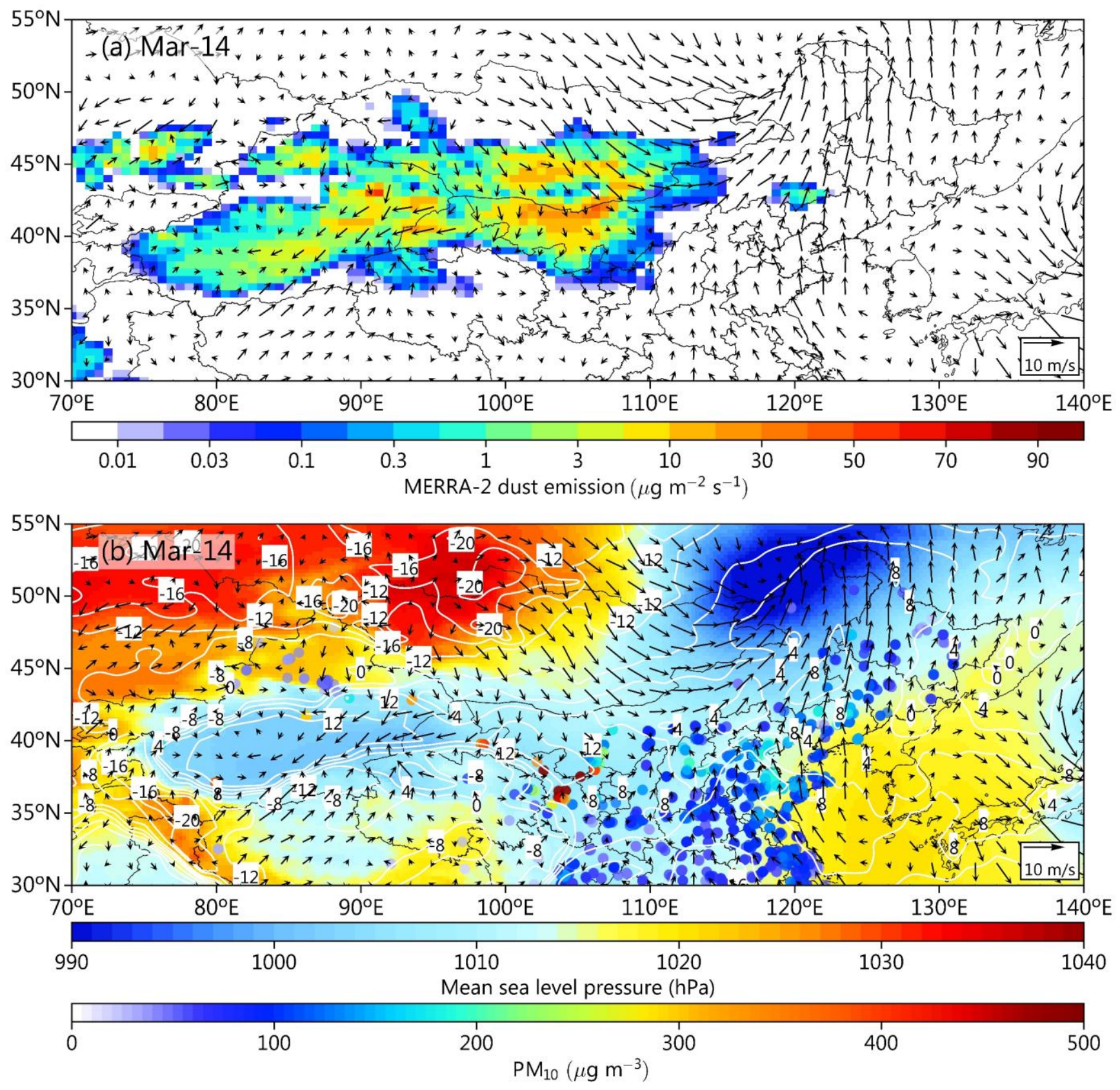

Figure 8: (a) MERRA-2 daily mean dust emissions for all size bins on March 14, 2021. (b) Daily mean sea level pressure (SLP, shading), temperature at $2 \mathrm{~m}$ (contour; ${ }^{\circ} \mathrm{C}$ ), and the observed daily mean $\mathrm{PM}_{10}$ concentrations from the CNEMC network on March 14, 2021. Overlaid on (a, b) are the ERA5 wind vectors at $10 \mathrm{~m}$. 


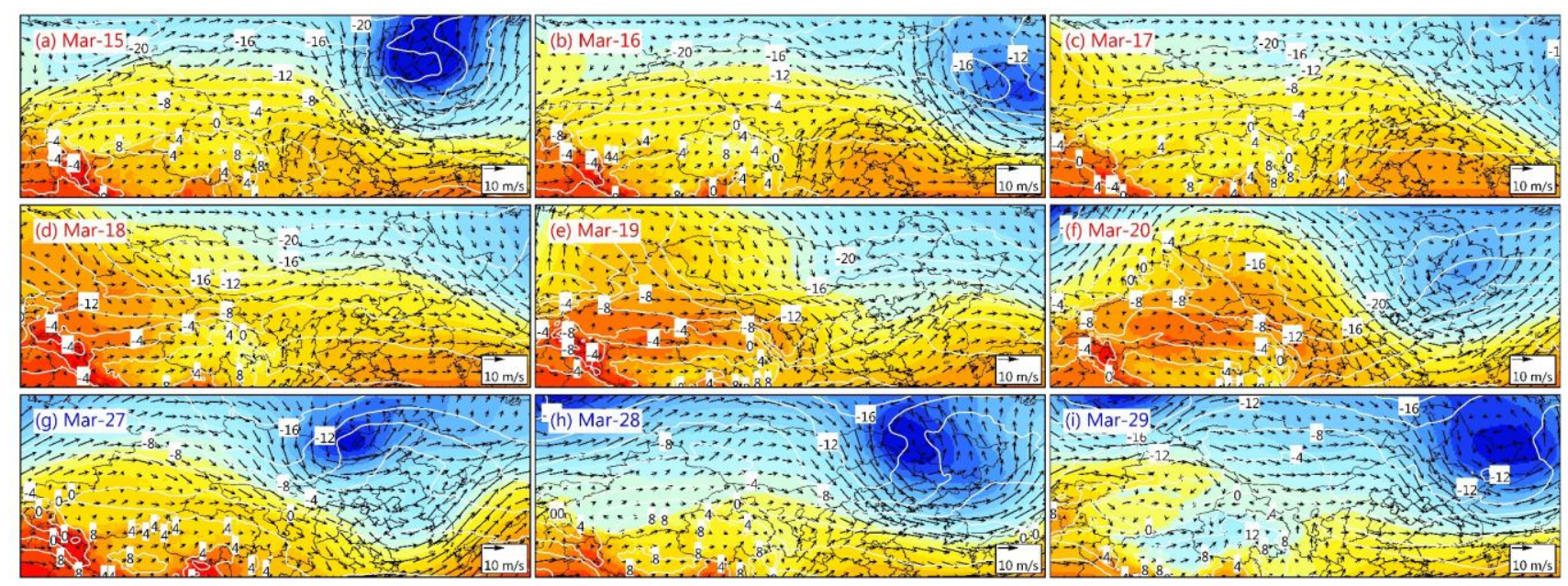

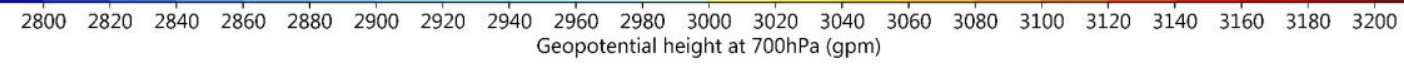

Figure 9: Pattern evolutions of ERA5 geopotential height (shading; gpm), temperature (contours; ${ }^{\circ} \mathrm{C}$ ), and wind vectors (black arrows; $\mathrm{m} \mathrm{s}^{-1}$ ) at 700 hPa on (a) March 15, (b) 16, (c) 17, (d) 18, (e) 19, (f) 20, (g) 27, (h) 28, and (i) $29,2021$. 
(a) March 2021

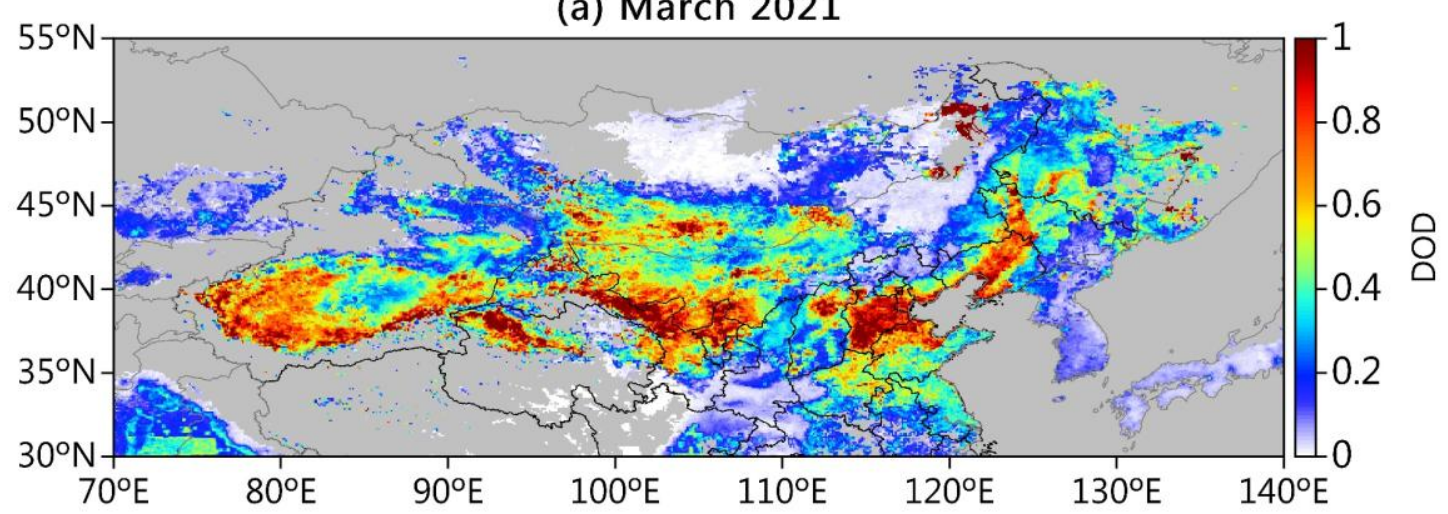

(b) March 2000-2020

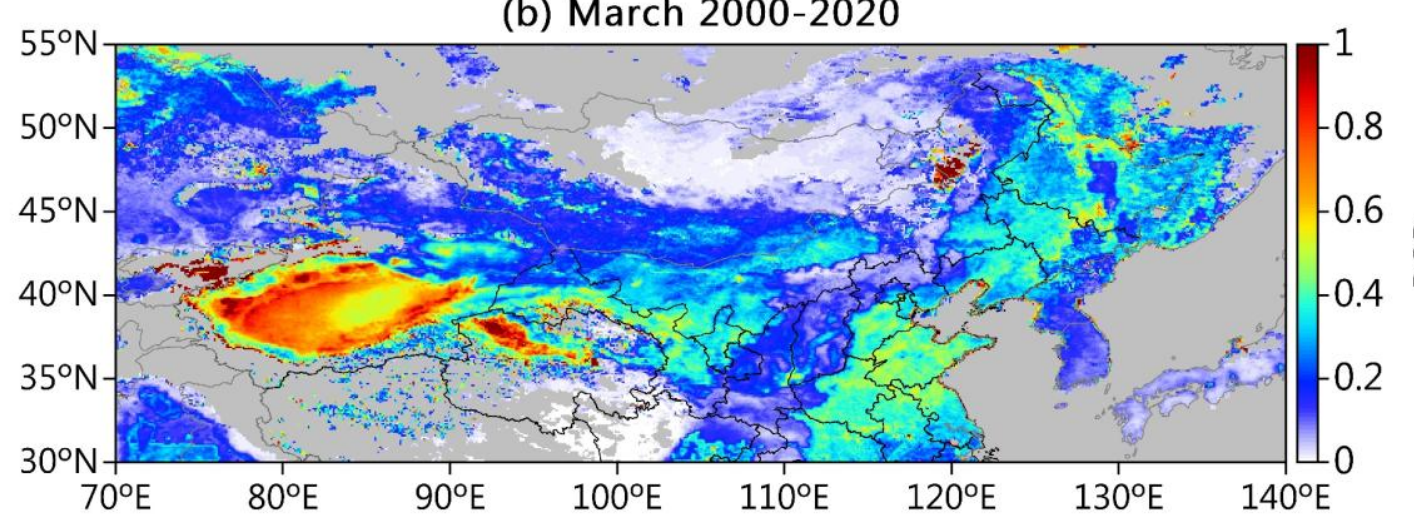

(c) March 2021 anomaly

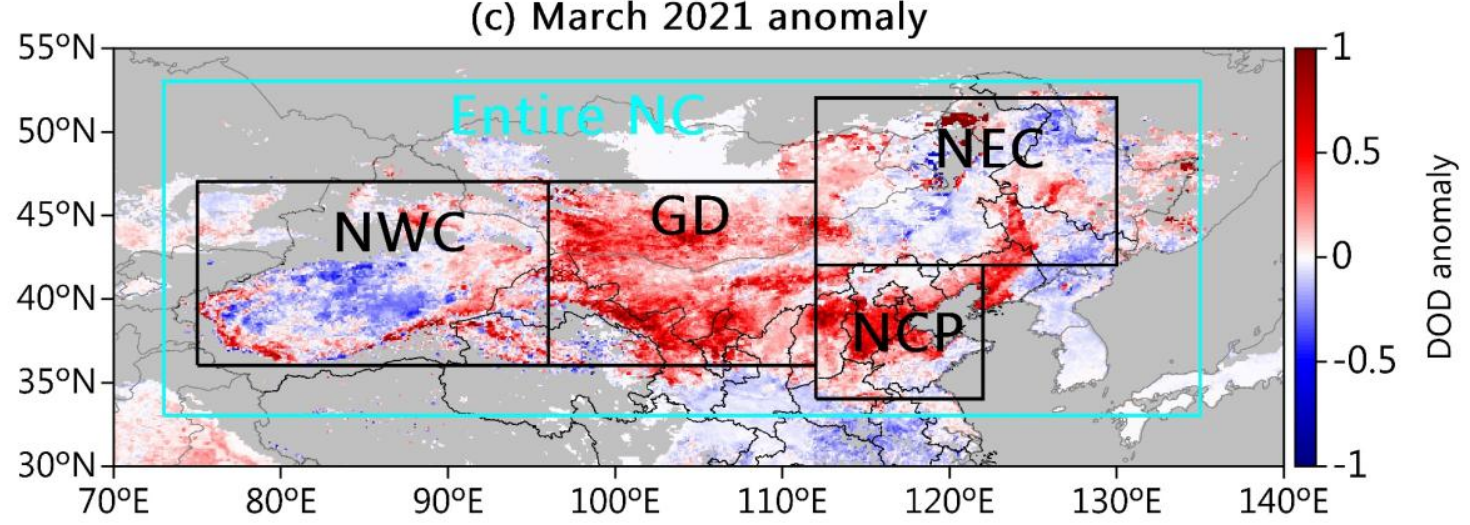

Figure 10: MODIS-retrieved DOD: (a) March 2021, (b) March climatology (2000-2020), and (c) March 2021 anomaly. Cyan and black boxes indicate the averaging areas for the DOD time series, including (a) the entire northern China region (entire $\mathrm{NC}^{\circ} \mathbf{3 3}^{\circ}-$

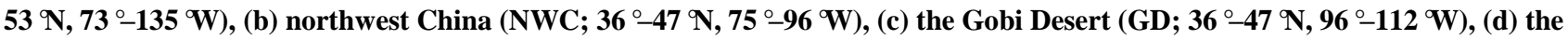
North China Plain $\left(\mathrm{NCP} ; 3^{\circ}-\mathbf{4 2}^{\circ} \mathrm{N}, \mathbf{1 1 2}^{\circ}-122^{\circ} \mathrm{W}\right)$, and (e) northeast China $\left(\mathrm{NEC} ; 4^{\circ}-5^{\circ} \mathrm{N}, \mathbf{1 1 2}^{\circ}-130^{\circ} \mathrm{W}\right)$. 

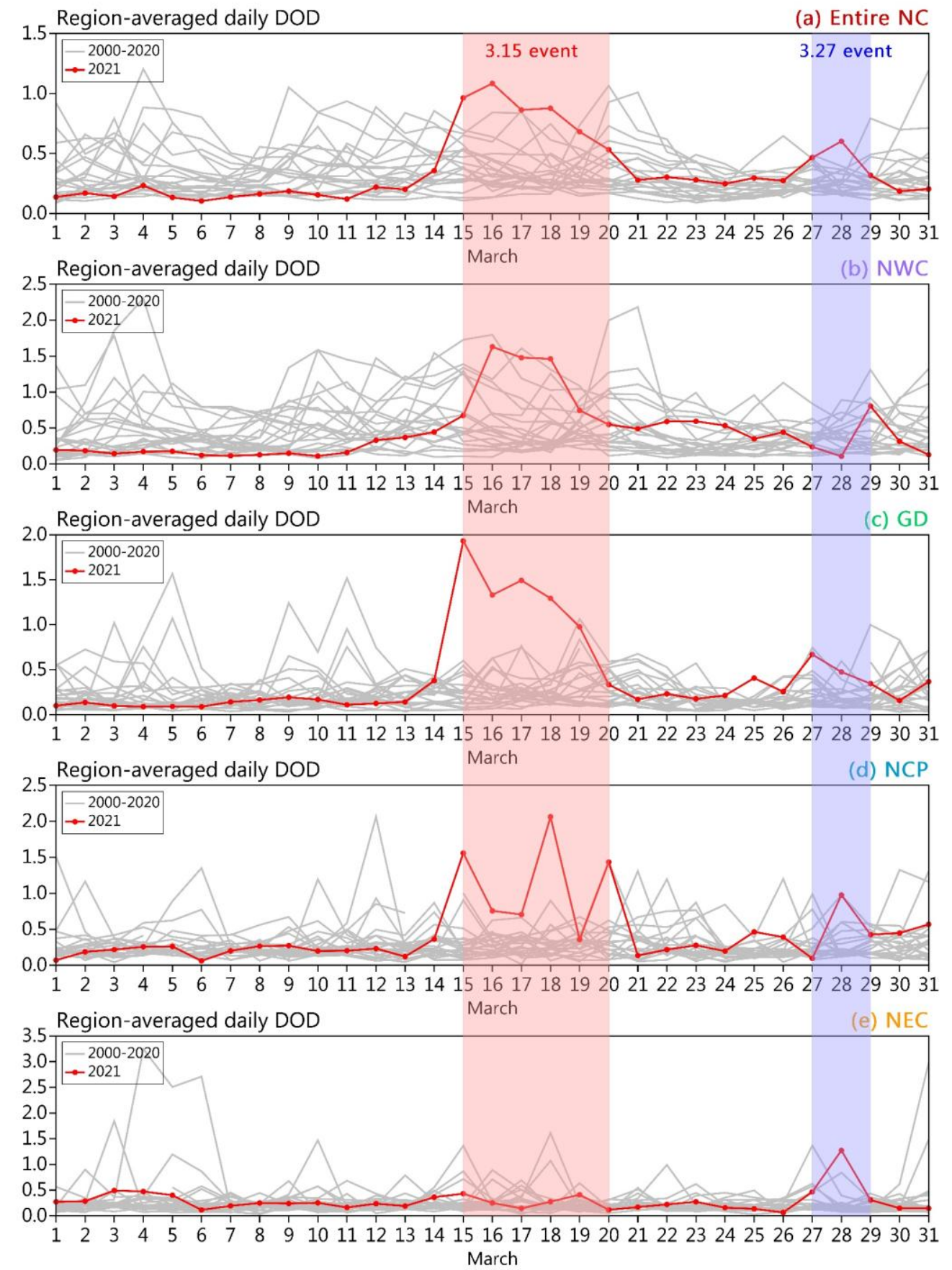

Figure 11: MODIS-retrieved daily mean DOD for March 2021 (thick lines with red dots) in comparison to the $2000-2020$ climatology (the year-to-year fluctuation range of daily DOD is represented by the thick gray line) in five regions, as defined in Fig. 10c. The days covered by the 3.15 and 3.27 events are marked in red and blue shading, respectively. 

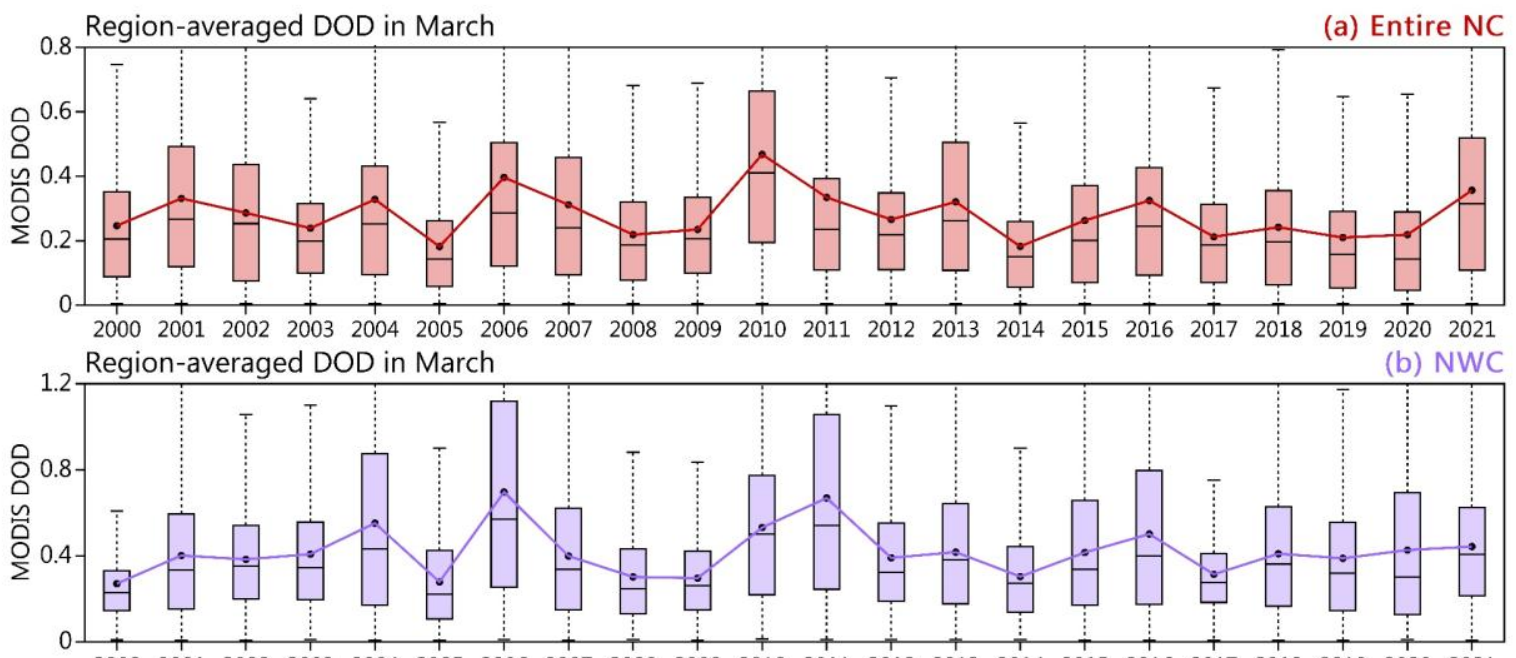

2000200120022003200420052006200720082009201020112012201320142015201620172018201920202021 Region-averaged DOD in March

(c) GD
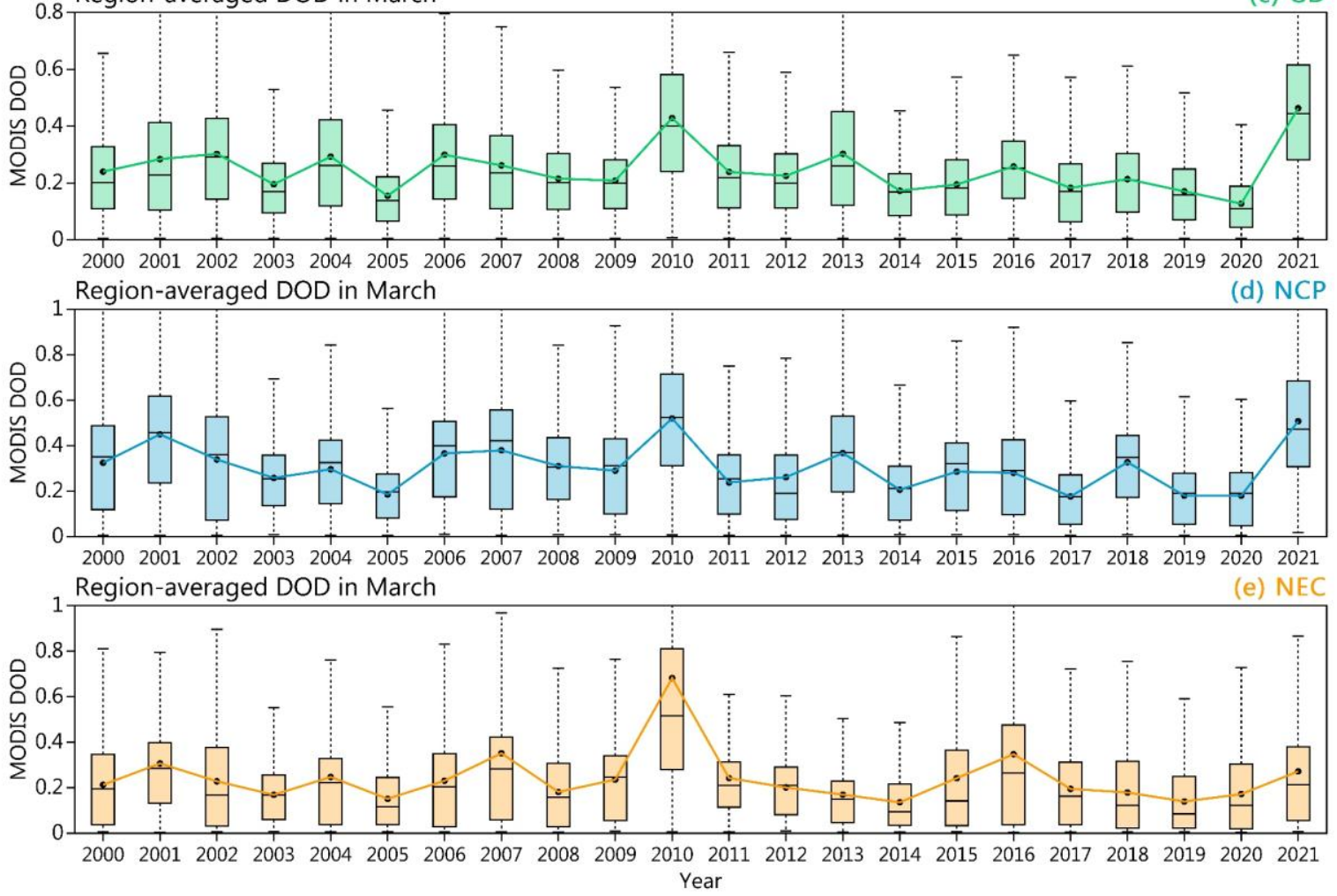

Figure 12: Time-series boxplots of MODIS-retrieved regional-averaged DOD over (a) the entire NC region, (b) NWC, (c) the GD, (d) the NCP, and (e) NEC in March from 2000 to 2021. 
(a) March 15-20 and 27-29, 2021

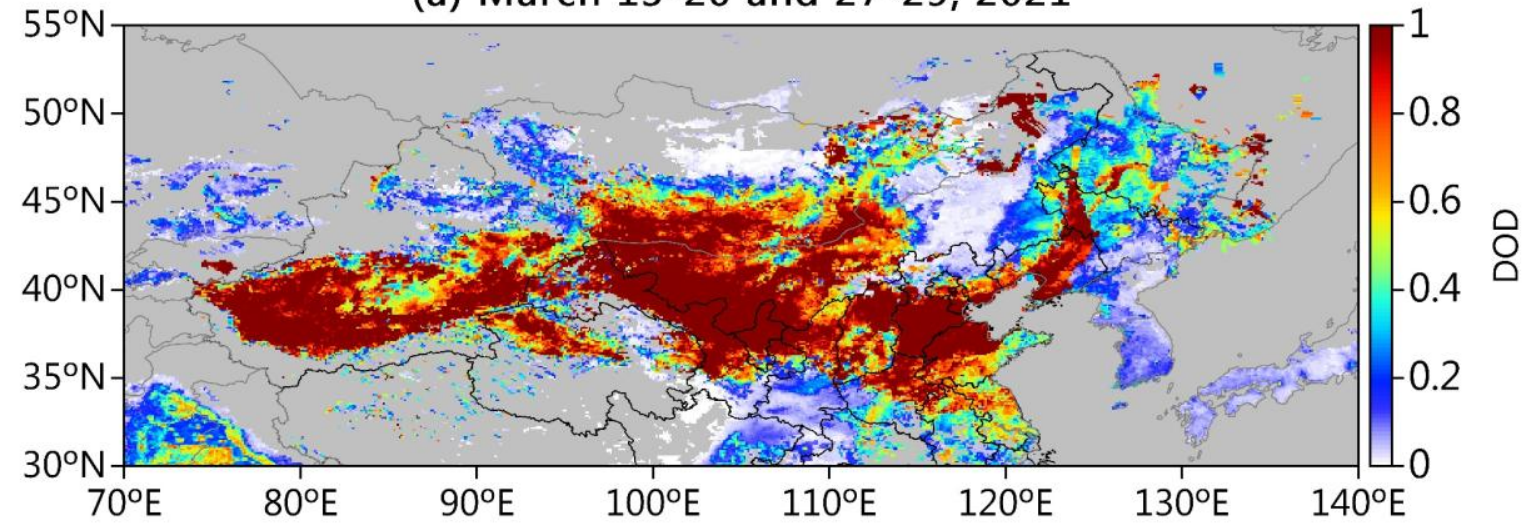

(b) March 15-20 and 27-29, 2000-2020

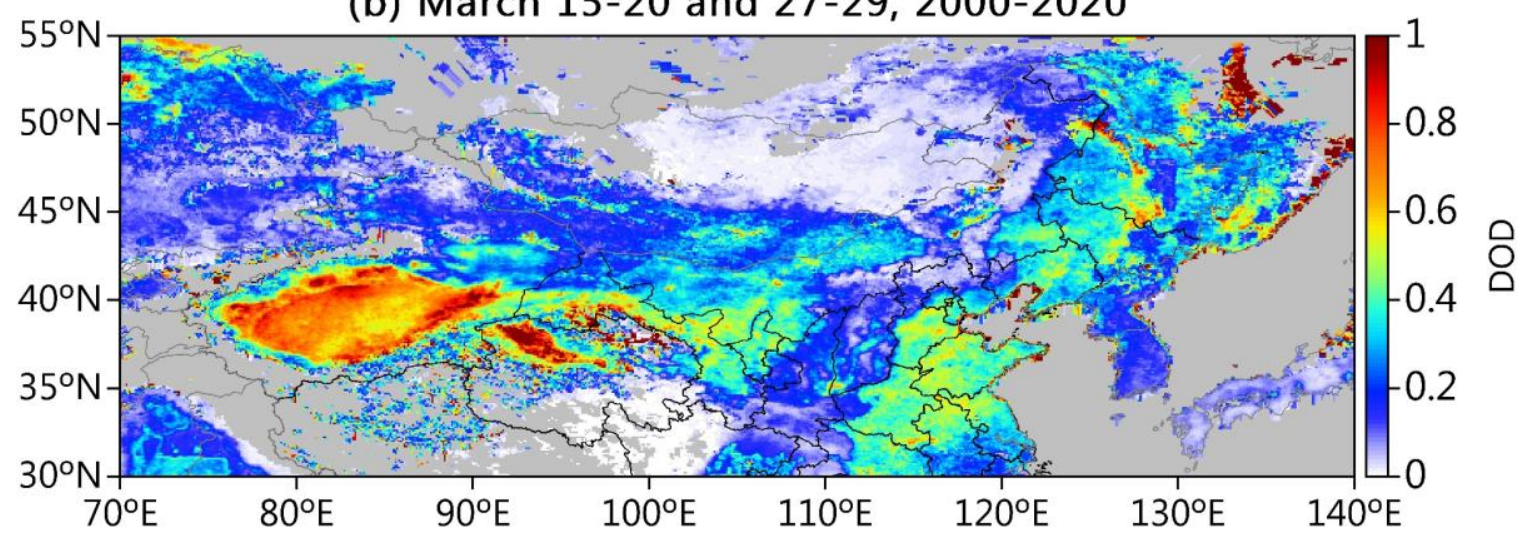

(c) March 15-20 and 27-29, 2021 anomaly

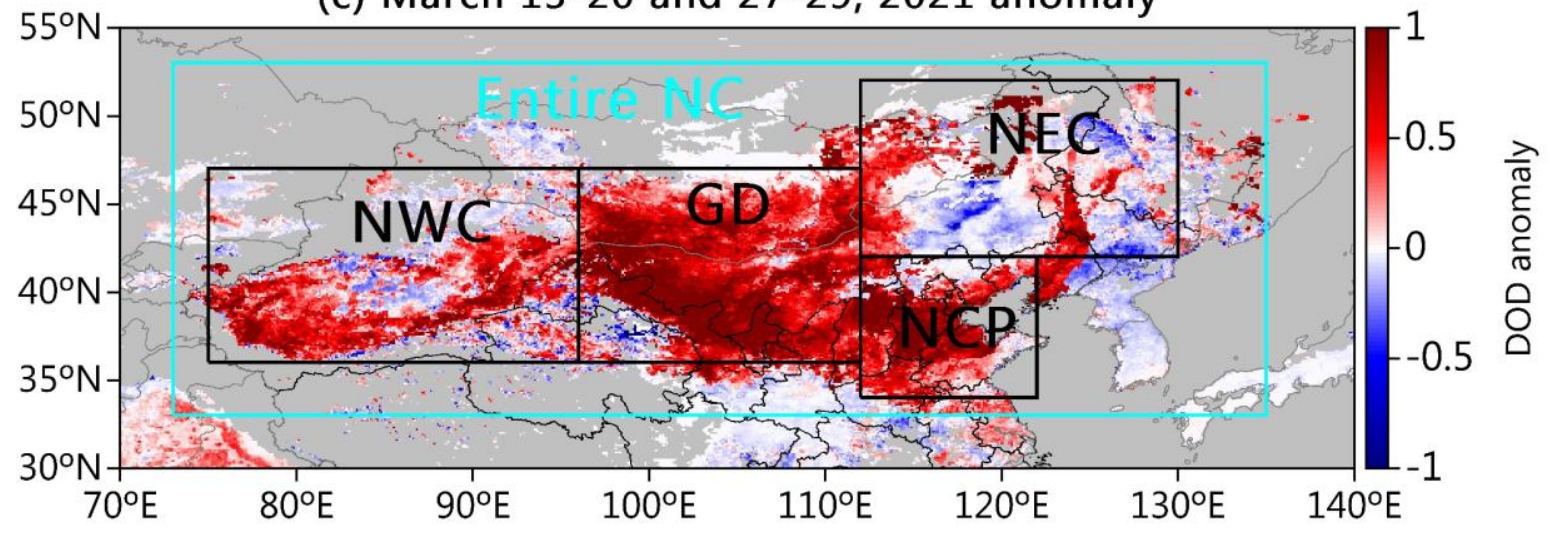

Figure 13: As in Fig. 10 but for the combined period of March 15-20 and 27-29. 

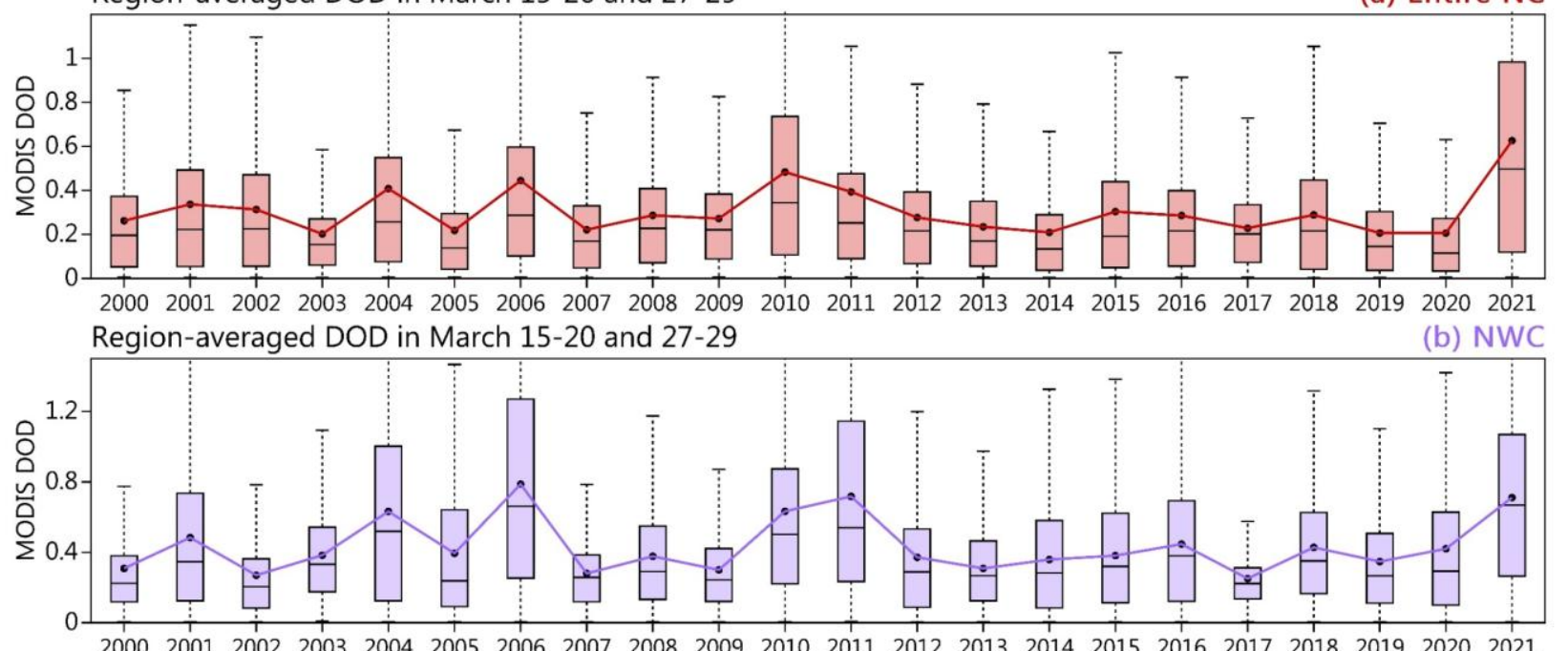
Region-averaged DOD in March 15-20 and 27-29

(c) GD

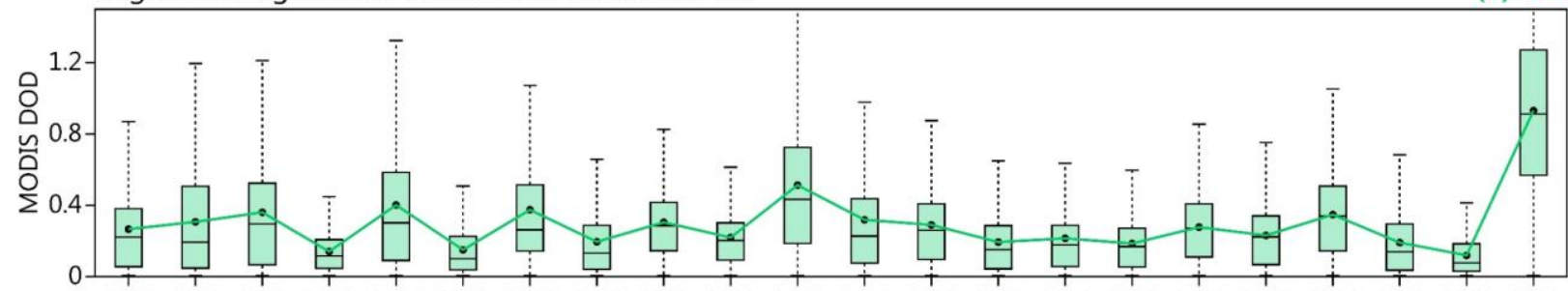

2000200120022003200420052006200720082009201020112012201320142015201620172018201920202021 Region-averaged DOD in March 15-20 and 27-29

(d) NCP
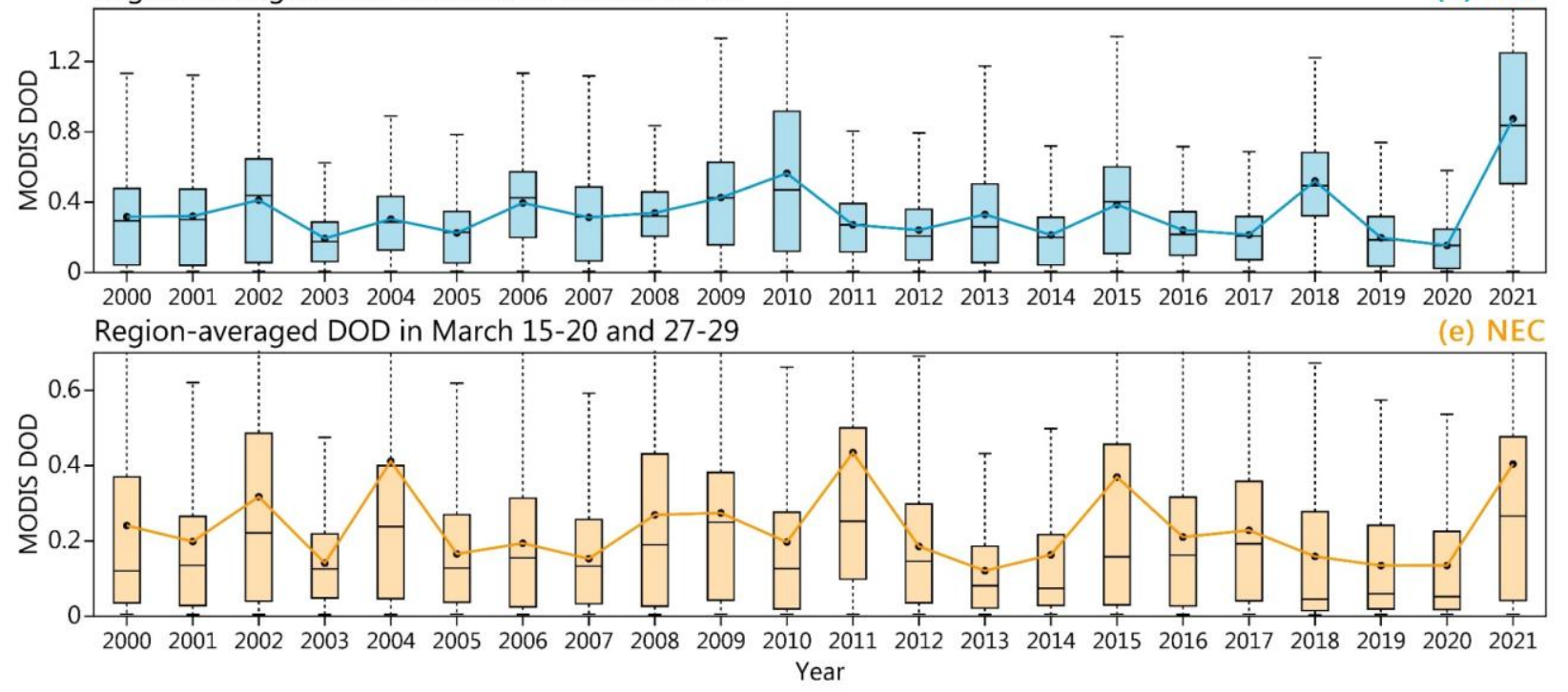

Figure 14: As in Fig. 12 but for the combined period of March 15-20 and 27-29. 

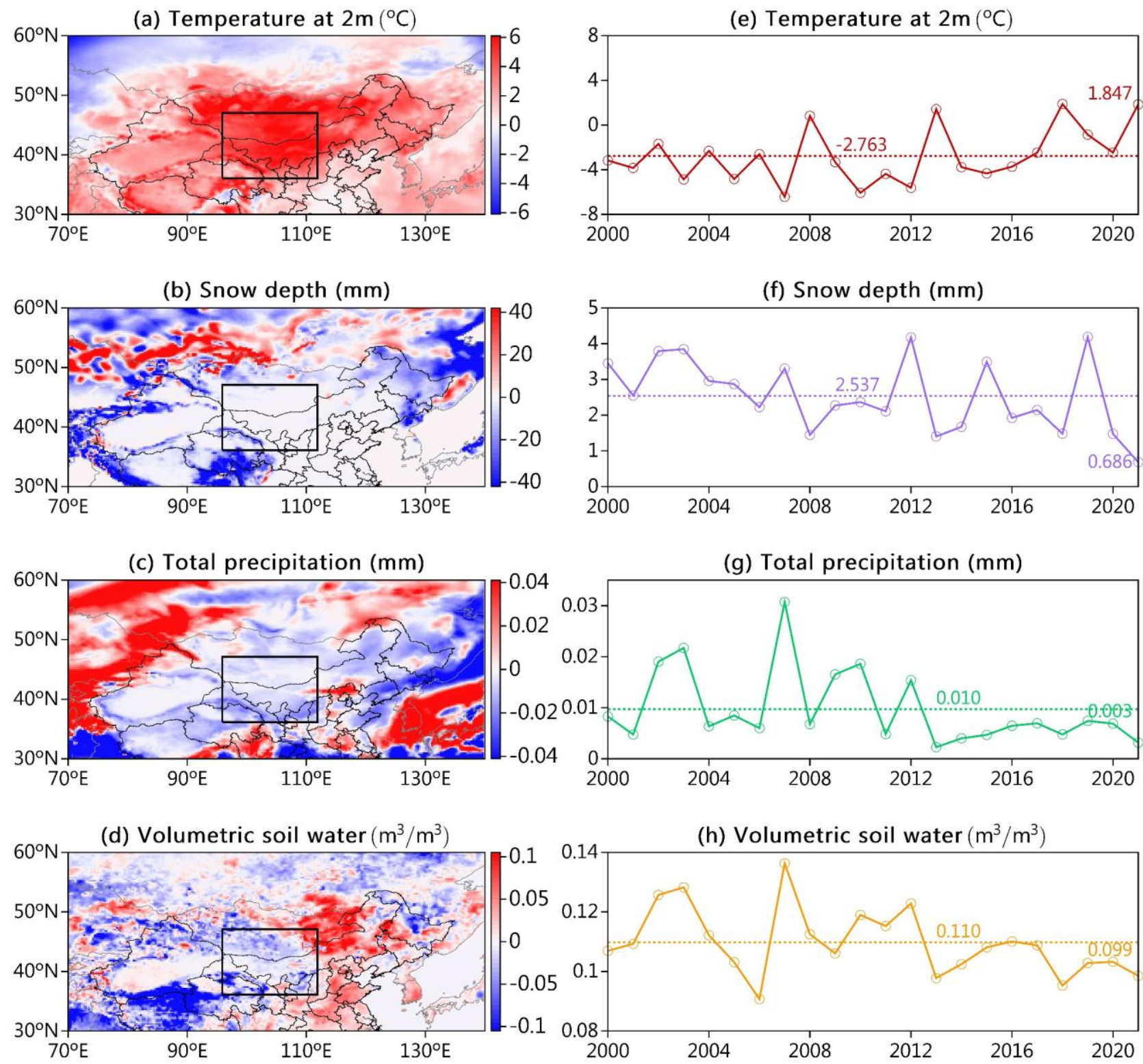

715 Figure 15: ERA5 meteorological anomalies two weeks before the 3.15 event: (a-d) anomalies of temperature at 2 m $\left({ }^{\circ} \mathrm{C}\right)$, and snow depth $(\mathrm{mm})$, total precipitation $(\mathrm{mm})$ and volumetric soil water $\left(\mathrm{m}^{3} / \mathrm{m}^{3}\right)$ with reference to the 2000-2020 climatology. (e-h) Time series of ERA5 meteorological factors two weeks before the 3.15 event averaged over the GD [black box in $(\mathrm{a}-\mathrm{d}): 36^{\circ}-47^{\circ} \mathrm{N}, 96^{\circ}-$ $\left.112^{\circ} \mathrm{W}\right]$. The numbers and dashed lines represent the multi-year averages and their locations, respectively. Also, the magnitude for 2021 is labeled. 